\title{
Genetic basis of hereditary hypophosphataemic rickets and phenotype presentation in children and adults
}

\author{
Nahid Tavana ${ }^{\circledR 1}$, Karuppiah Thilakavathy ${ }^{\circledR 1}{ }^{1,2}$, Marina L. Kennerson ${ }^{\circledR 3-5}$, Tzer Hwu Ting ${ }^{\circledR 6}$ \\ ${ }^{1}$ Department of Biomedical Science, Faculty of Medicine and Health Sciences, Universiti Putra Malaysia, Selangor, Malaysia \\ ${ }^{2}$ Genetics and Regenerative Medicine Research Group, Faculty Medicine and Health Sciences, Universiti Putra Malaysia, Selangor, \\ Malaysia \\ ${ }^{3}$ Northcott Neuroscience Laboratory, ANZAC Research Institute, University of Sydney, Concord, NSW, Australia \\ ${ }^{4}$ Sydney Medical School, University of Sydney, Sydney, NSW, Australia \\ ${ }^{5}$ Molecular Medicine Laboratory, Concord Hospital, Concord, NSW, Australia \\ ${ }^{6}$ Department of Paediatrics, Faculty of Medicine and Health Sciences, Universiti Putra Malaysia, Selangor, Malaysia
}

\begin{abstract}
Hypophosphataemic rickets (HR) is a genetic disorder causing defects in the renal handling of phosphorus, resulting in rickets. HR can be classified into two groups. First - with excess fibroblast growth factor 23 (FGF23) levels, which are due to gene mutations in extrarenal factors and include X-linked dominant hypophosphataemic rickets (XLHR), autosomal dominant hypophosphataemic rickets (ADHR), autosomal recessive hypophosphataemic rickets (ARHR), and hypophosphataemic rickets with hyperparathyroidism. Second — with normal or low FGF23, which are caused by gene mutations in renal tubular phosphate transporters and include hereditary hypophosphataemic rickets with hypercalciuria $(\mathrm{HHRH})$ and $\mathrm{X}$-linked recessive hypophosphataemic rickets. The radiographical changes and clinical features of rickets in various types of HR are similar but not identical. Short stature, bone deformities mainly in the lower limbs, and dental problems are typical characteristics of HR. Although the initial diagnosis of HR is usually based on physical, radiological, and biochemical features, molecular genetic analysis is important to confirm the diagnosis and differentiate the type of HR. In this review, we describe clinical and biochemical features as well as genetic causes of different types of HR. The clinical and biochemical characteristics presented in this review can help in the diagnosis of different types of HR and, therefore, direct genetic analysis to look for the specific gene mutation. (Endokrynol Pol 2021; 72 (4): 366-394)
\end{abstract}

Key words: hypophosphatemia; hypophosphataemic rickets; phenotype; PHEX; FGF23; clinical features; mutation; XLHR

\section{Introduction}

Rickets is a childhood bone disorder characterized by defective growth plate mineralization leading to deformity in the growing skeleton. Adults are also vulnerable to a similar condition of rickets, known as osteomalacia, which causes softening of the bone. Osteomalacia occurs after the closure of the epiphyses, the end part of bones that is the most active in osteogenesis [1-3]. Deficiency of calcium, phosphorous, or vitamin $\mathrm{D}$ are known causes of rickets [3]. Chronic phosphate deficiency causes poor bone mineralization leading to rickets and osteomalacia [4].

Hypophosphataemic rickets (HR) was first described as vitamin D-resistant rickets by Fuller Albright because a patient did not respond to vitamin $\mathrm{D}$ treatment [5], although vitamin D deficiency was then the most common cause of rickets. Unlike vitamin D deficiency rickets, HR is due to mutations in genes involved in phosphate regulation and is characterized by low serum phosphate levels due to renal phosphate loss $[2,6,7]$.

Serum levels of phosphate are mainly regulated by 1,25-dihydroxyvitamin $\mathrm{D}\left[1,25(\mathrm{OH})_{2} \mathrm{D}\right]$, parathyroid hormone (PTH) and fibroblast growth factor 23 (FGF23). The action of $1,25(\mathrm{OH})_{2} \mathrm{D}$ is to increase the absorption of phosphate from the intestine and reduce the synthesis and secretion of PTH. In the kidney, both PTH and FGF23 contribute to renal reabsorption of phosphate by suppressing the expression of type 2 co-transporters of sodium/phosphate (NaPi2a and NaPi2c). In addition, FGF23 decreased the production of $1,25(\mathrm{OH})_{2} \mathrm{D}$ by inhibiting $25-\mathrm{OH}$ vitamin D 1- $\alpha$ hydroxylase, resulting in reduced phosphate absorption from the intestine. FGF23 plays its role in the presence of Klotho, which is a transmembrane protein. The FGF receptor is activated by intact FGF23 when the co-receptor Klotho is present [1,7]. Depending on whether FGF23 is involved, HR can be classified into two groups: HR with excess FGF23 levels due to mutations in genes not predominantly expressed in the kidneys, and 


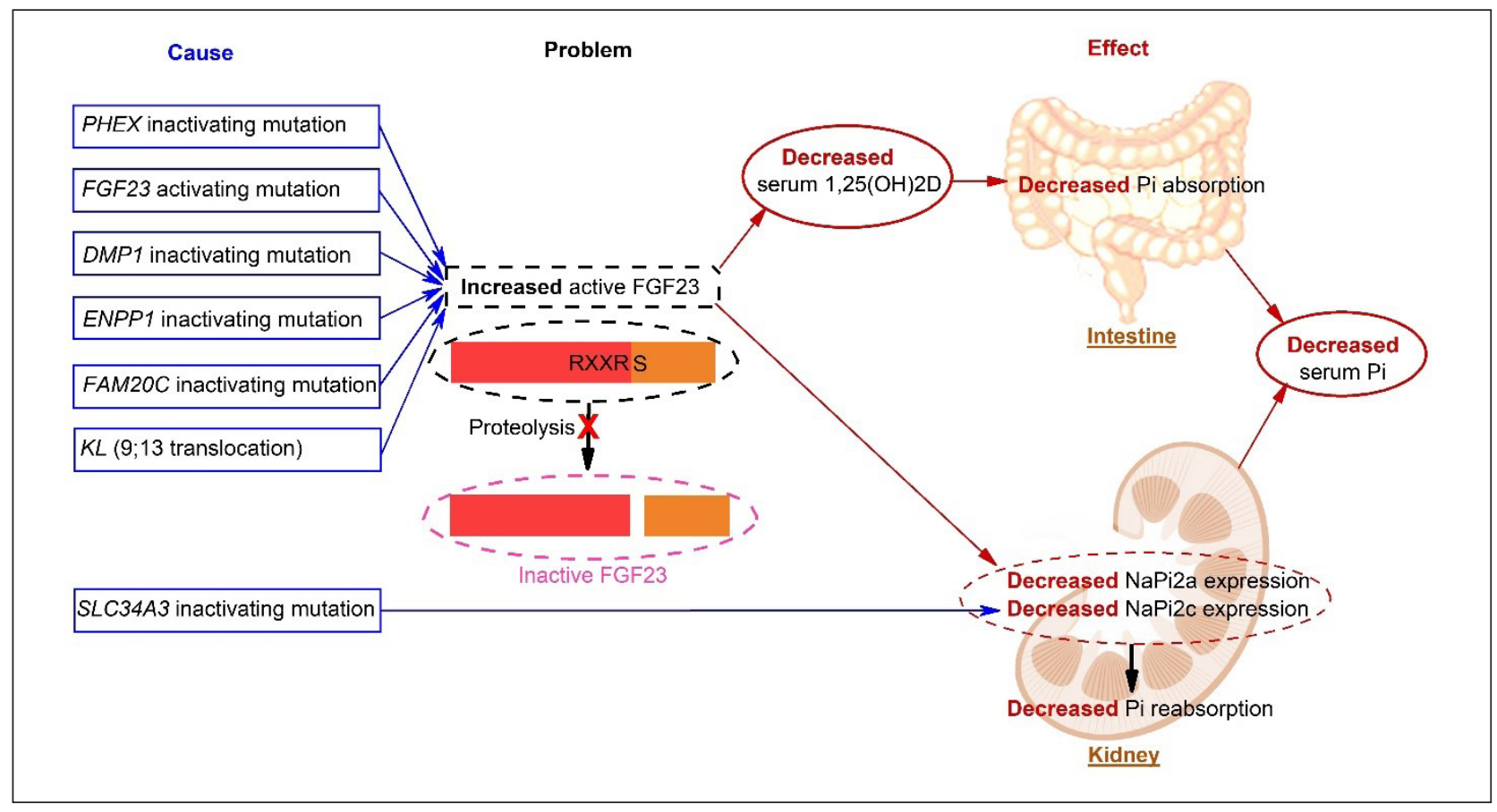

Figure 1. Summary of HR pathogenesis. Mutations in PHEX (phosphate regulating endopeptidase homologue, X-linked), FGF23 (fibroblast-growth-factor 23), DMP1 (dentin matrix acidic phosphoprotein 1), ENPP1 (ectonucleotide pyrophosphatase/phosphodiesterase 1), FAM20C (family with sequence similarity 20, member C), and KL (Klotho) increase active form of FGF23 in serum. Activating mutations in FGF23 and inactivating mutations in PHEX and FAM20C lead to the prevention of proteolytic cleavage of FGF23 between $R$ (Arg179) and S (Ser180). Elevated FGF23 results in decreased serum Pi (phosphate) through the intestine and kidney. Mutations in SLC34A3 (solute carrier family 34) cause decreased reabsorption of phosphate in the kidney and thus decreased serum Pi without the mediation of FGF23

HR with normal or low FGF23 caused by gene mutations in renal tubular phosphate transporters [7, 8] (see Fig. 1).

Normally, individuals at different ages show different levels of serum phosphate. The concentration of phosphate is higher in infants compared to adolescents [2]. For instance, normal levels of serum phosphate for 1-3 and 16-19 years of age range from 3.8 to $6.5 \mathrm{mg} / \mathrm{dL}$ and from 2.7 to $4.7 \mathrm{mg} / \mathrm{dL}$, respectively [7]. The best method of estimating renal phosphate wasting is the ratio of the tubular maximum reabsorption rate of phosphate to the glomerular filtration rate (TmP/GFR). In the presence of hypophosphataemia, low TmP/GFR indicates renal phosphate loss [7]. Other typical biochemical findings in HR include increased serum alkaline phosphatase (ALP) levels and normal or slightly increased PTH levels. Nevertheless, PTH levels are markedly elevated in HR with hyperparathyroidism (Klotho translocation) [1].

The clinical manifestations of HR change at different stages of life in the same individual and vary between different individuals with the same gene mutation, even within the same family. The radiographical changes and clinical features of rickets in various types of HR are similar. Short stature, bone deformities mainly in the lower limbs, and dental problems are typical characteristics of $\operatorname{HR}[2,6,8]$. A review of different types of HR, as well as the genetic causes, physical characteristics, and biochemical findings of each type is presented.

\section{Hypophosphataemic rickets with increased FGF23 levels}

\section{$X$-linked dominant hypophosphataemic rickets}

X-linked dominant hypophosphataemic rickets (XLHR; MIM\#307800) is the most common inherited form of HR, which accounts for more than $80 \%$ of familial hypophosphataemic rickets [9]. It is a rare disease with a prevalence of 1 per 20,000 live births [8]. Inactivating mutations in the phosphate regulating endopeptidase homologue, X-linked (PHEX; MIM\#300550) gene lead to XLHR. Osteocytes produce more FGF23 due to inactivity or decreased activity of PHEX, leading to increased FGF23 circulating levels [10]. Elevated FGF23 levels decrease renal reabsorption of phosphate and absorption of phosphate from the gut into the bloodstream, leading to hypophosphataemia (see Fig. 1).

The PHEX gene mutation was first described in 1995 [11]. Subsequent studies of HR patients, as shown in Table 1, have reported several mutations in PHEX using 


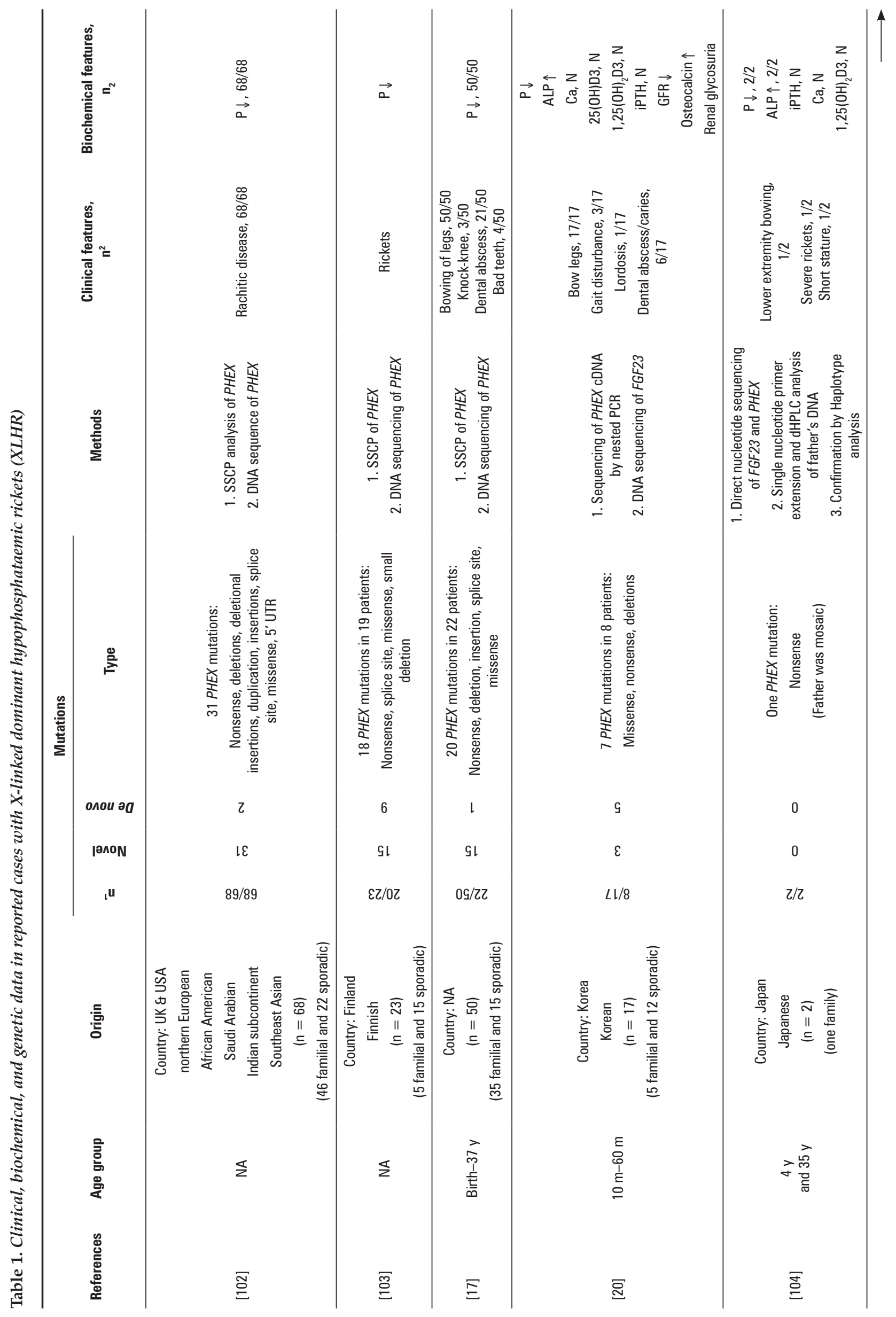




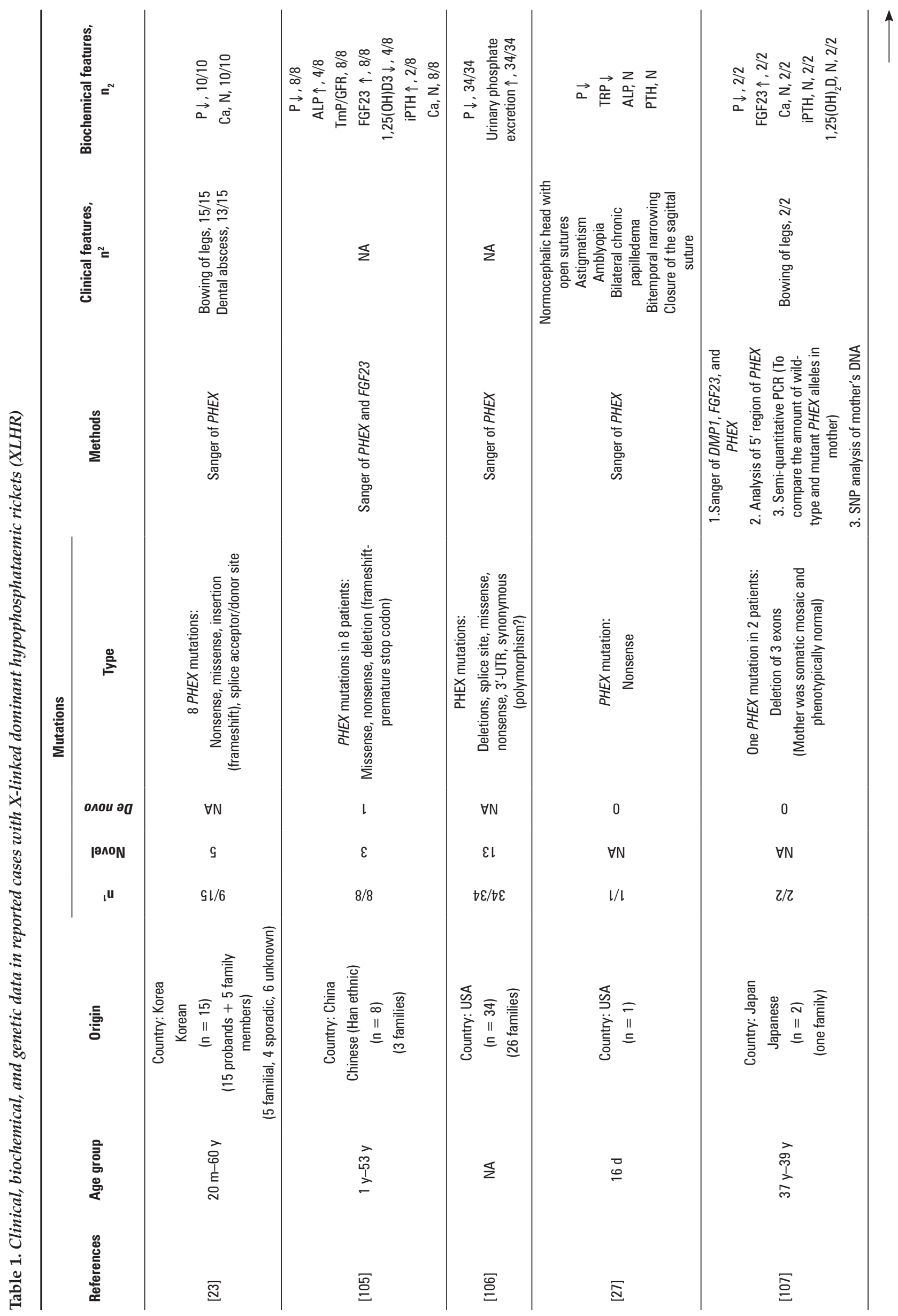




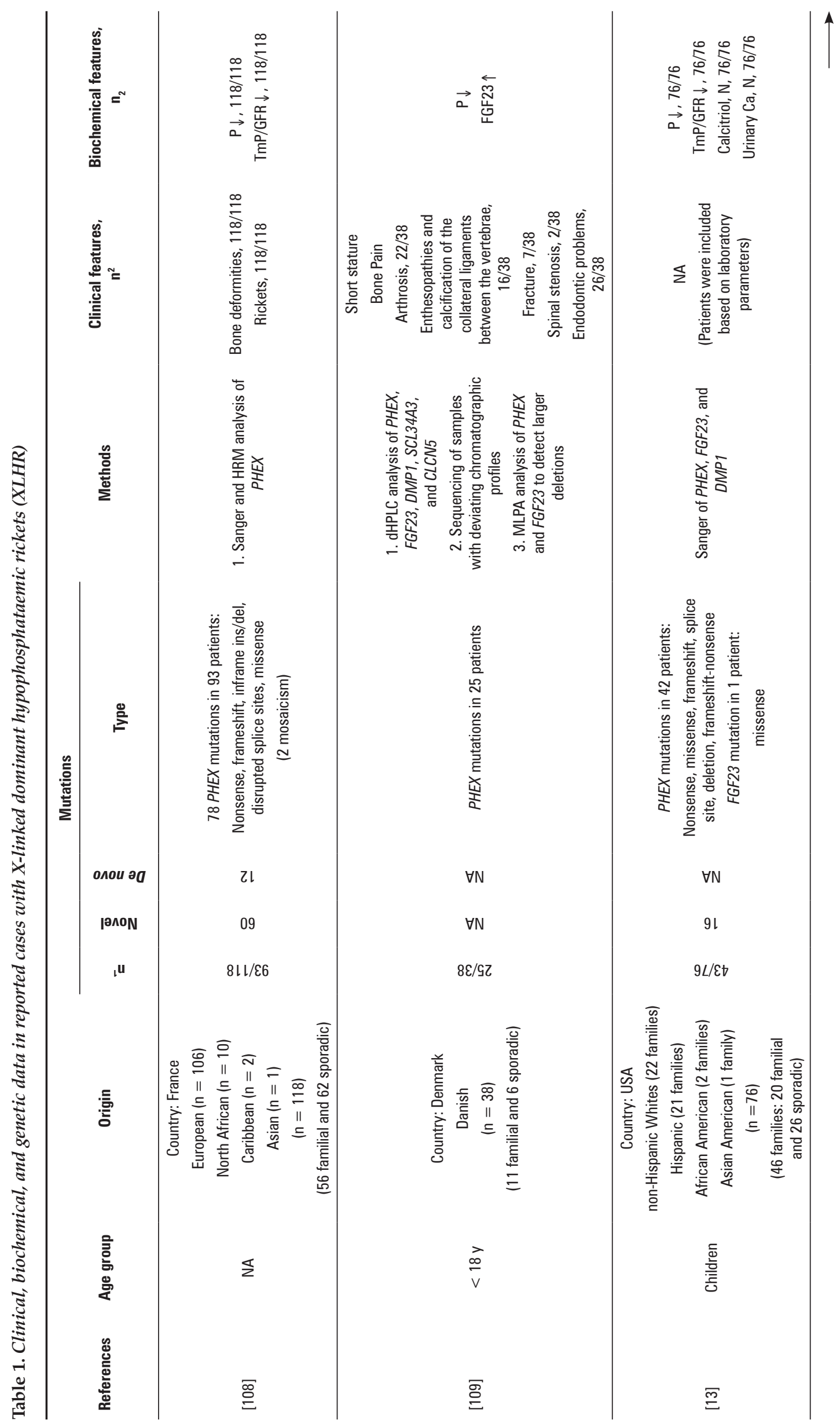




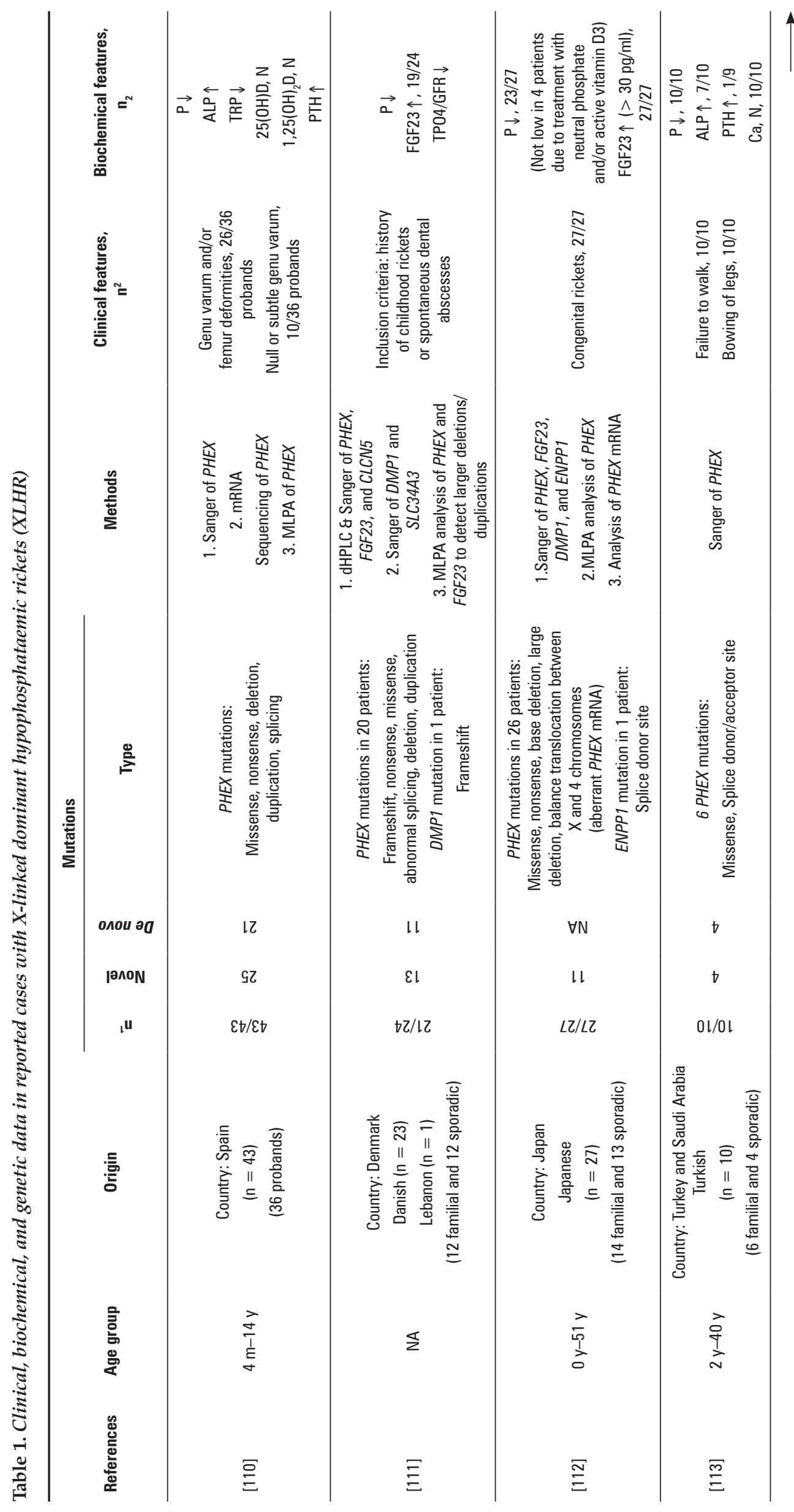




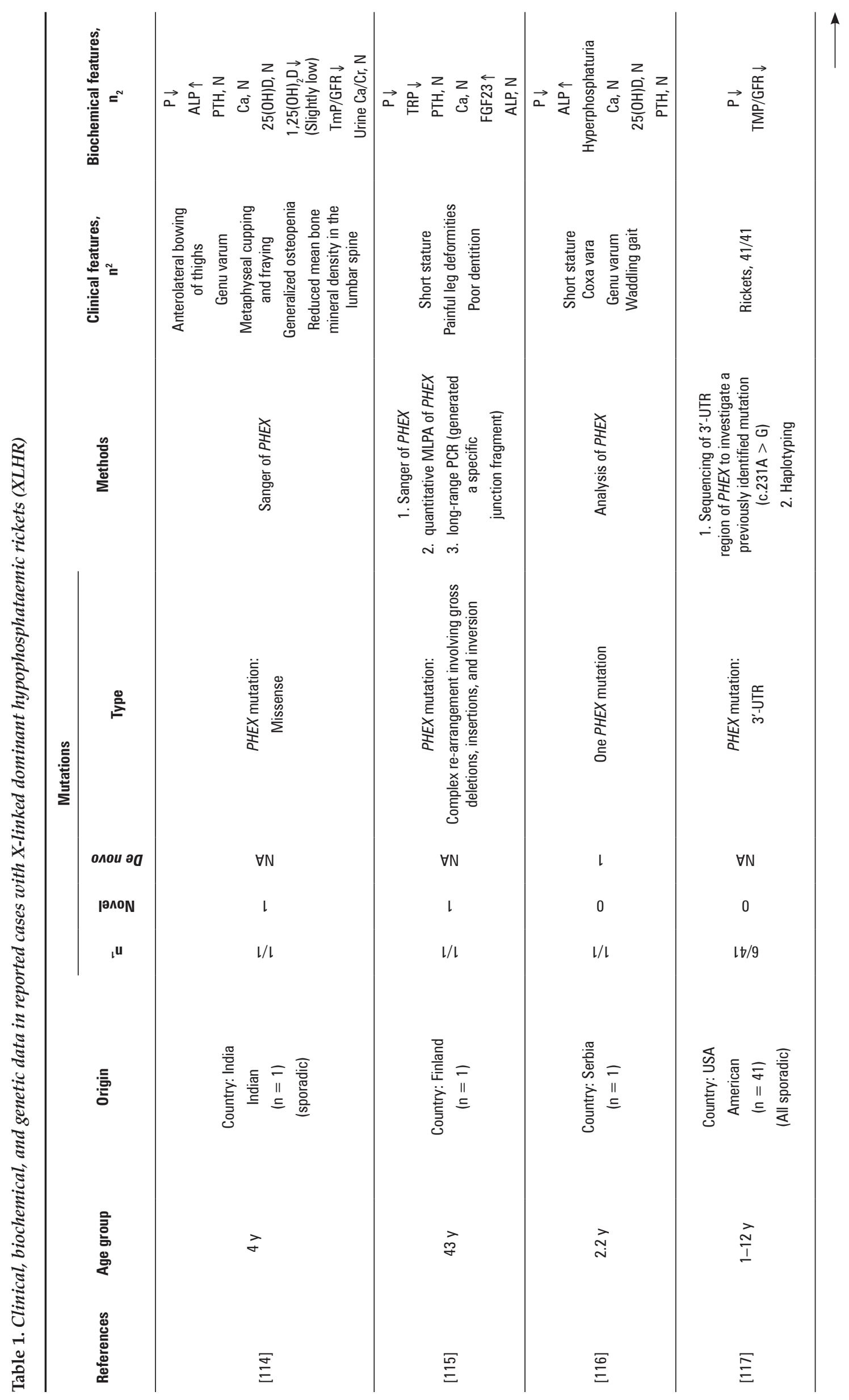




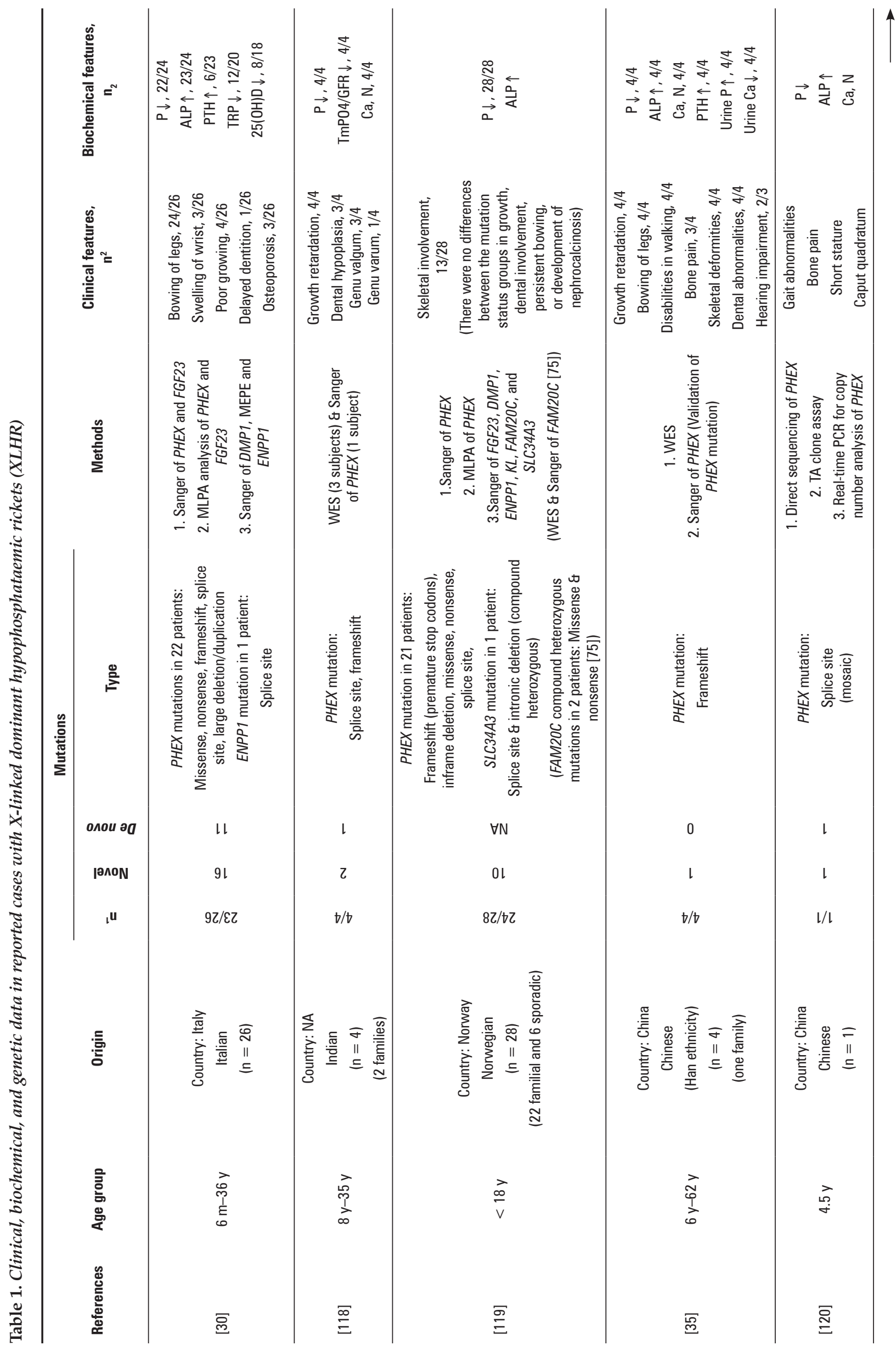




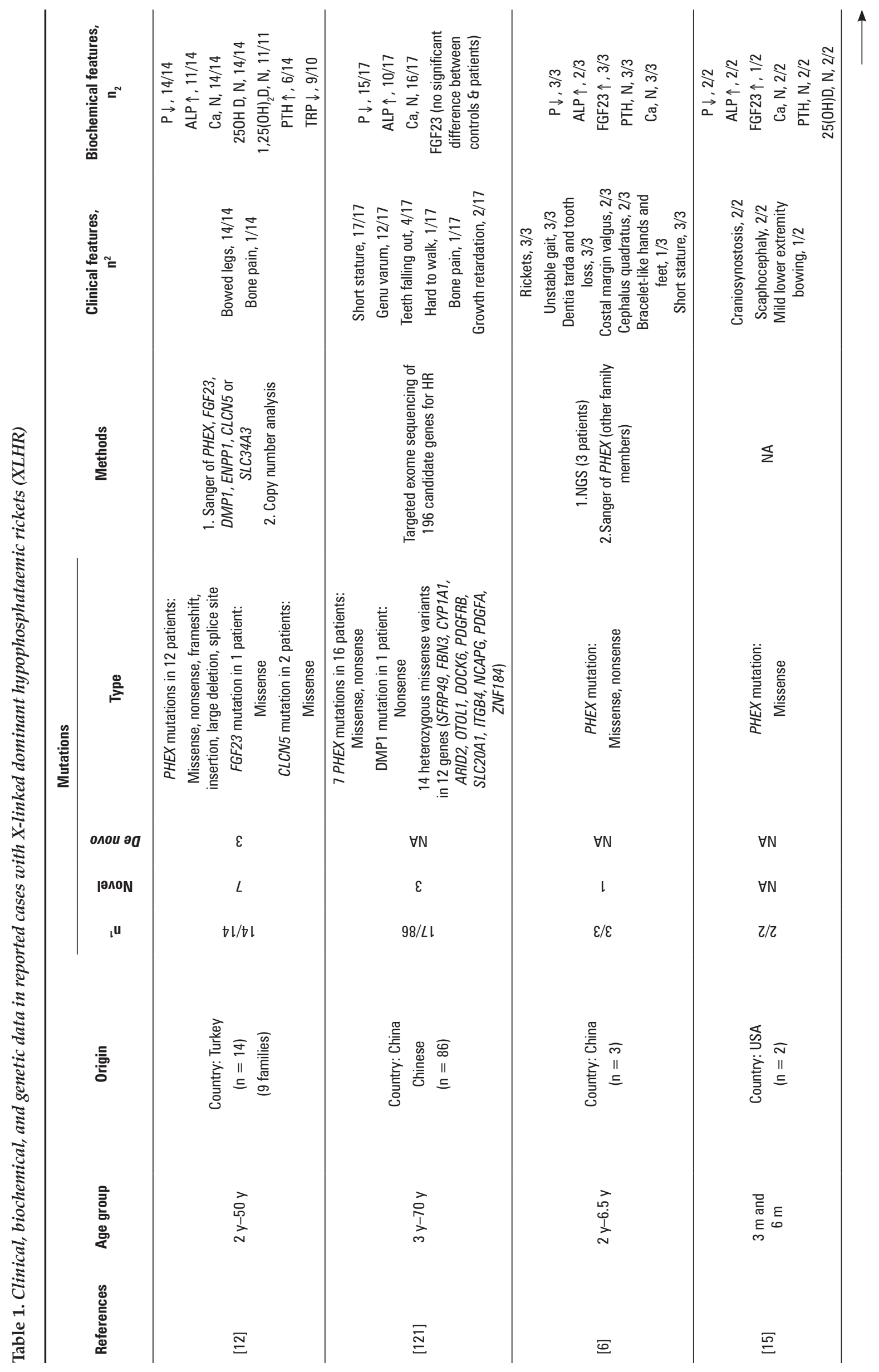




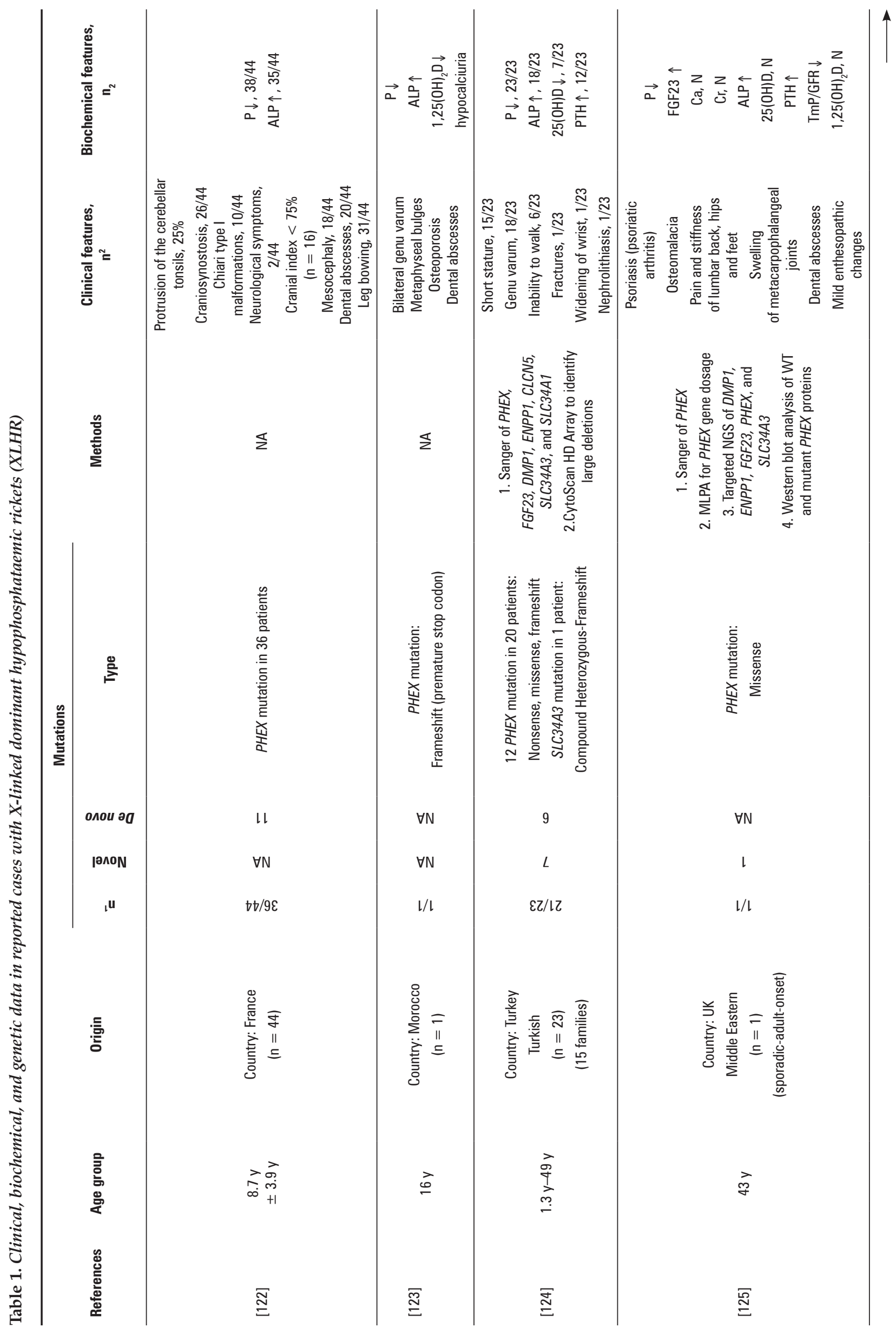




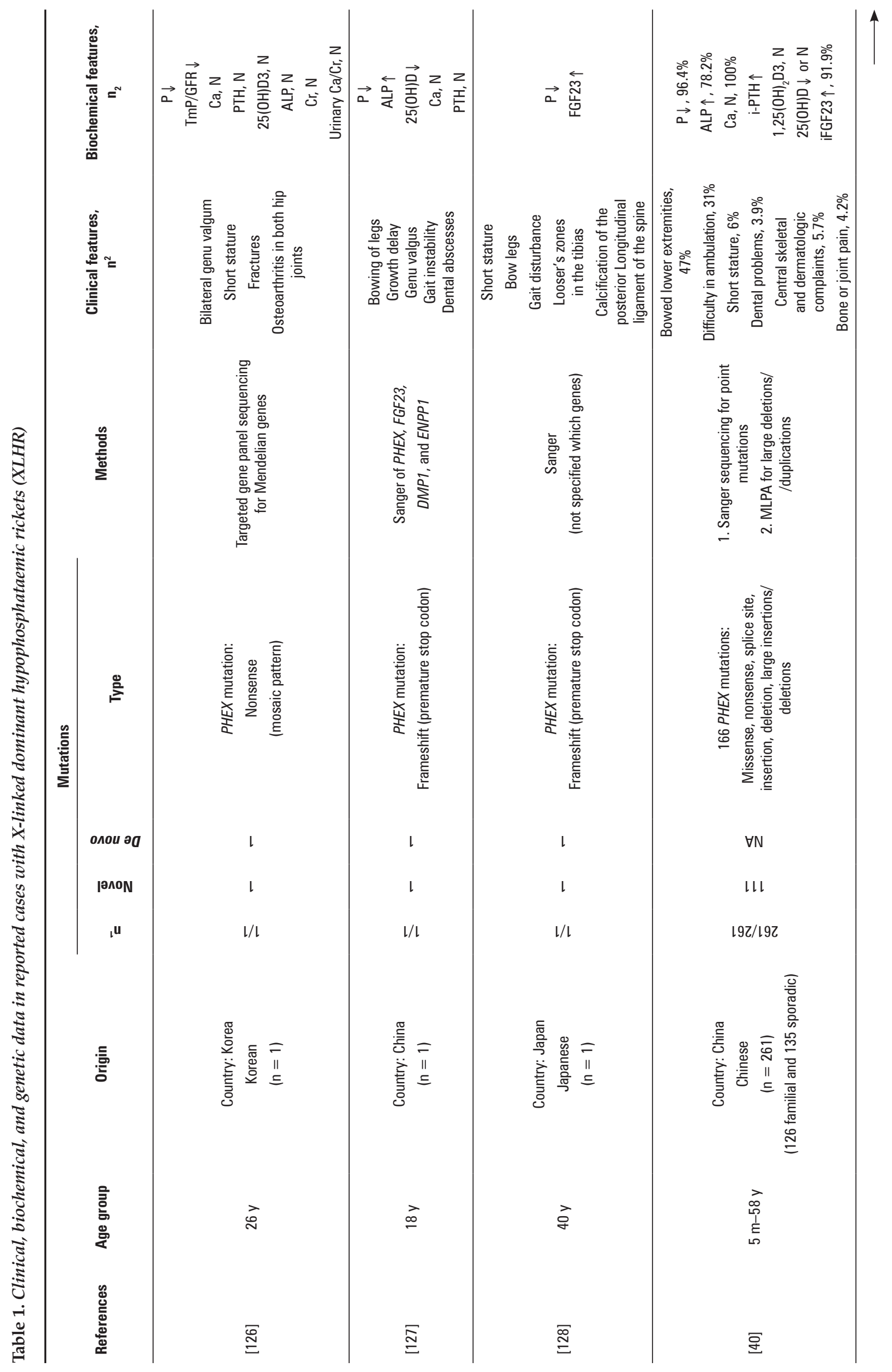




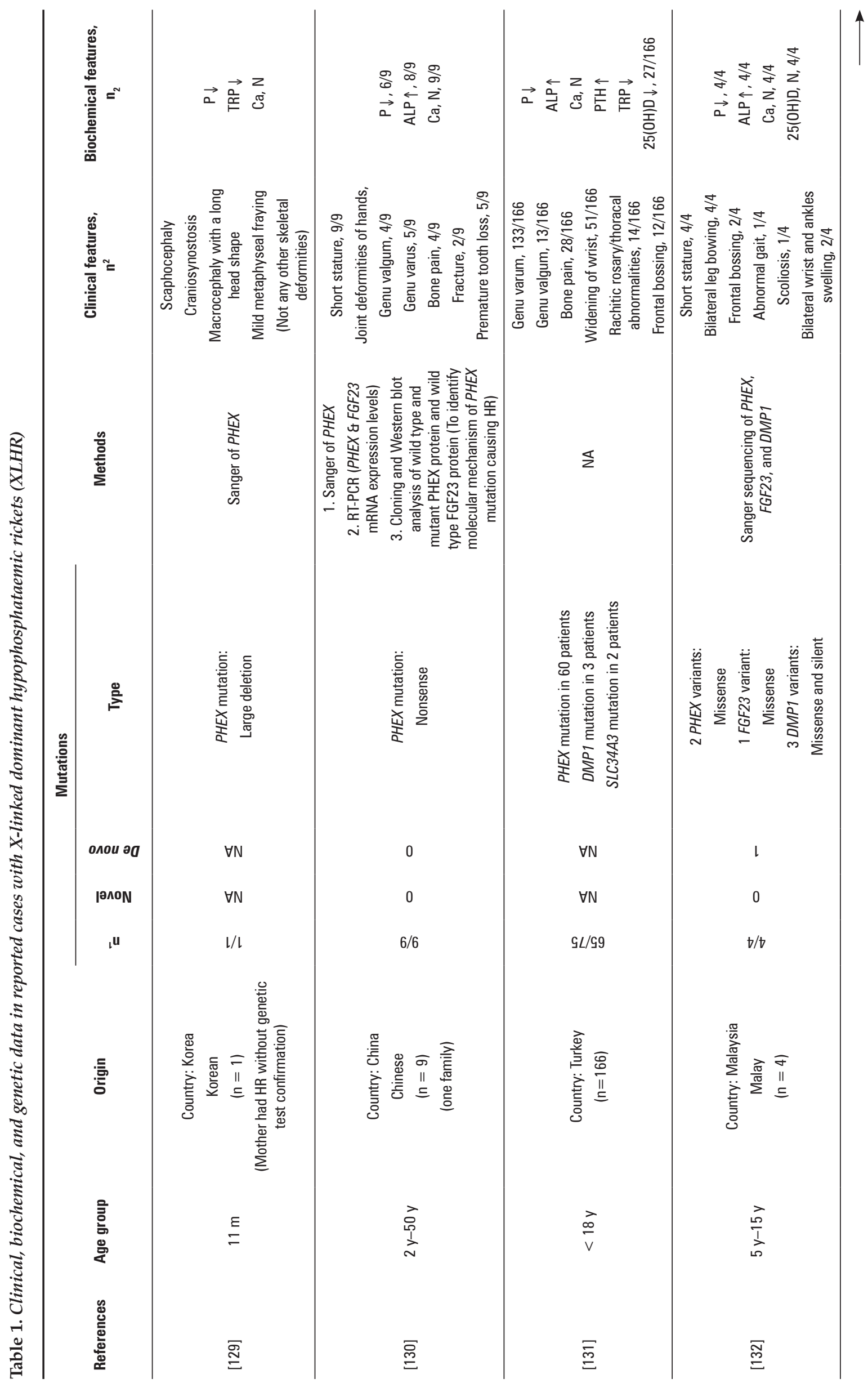




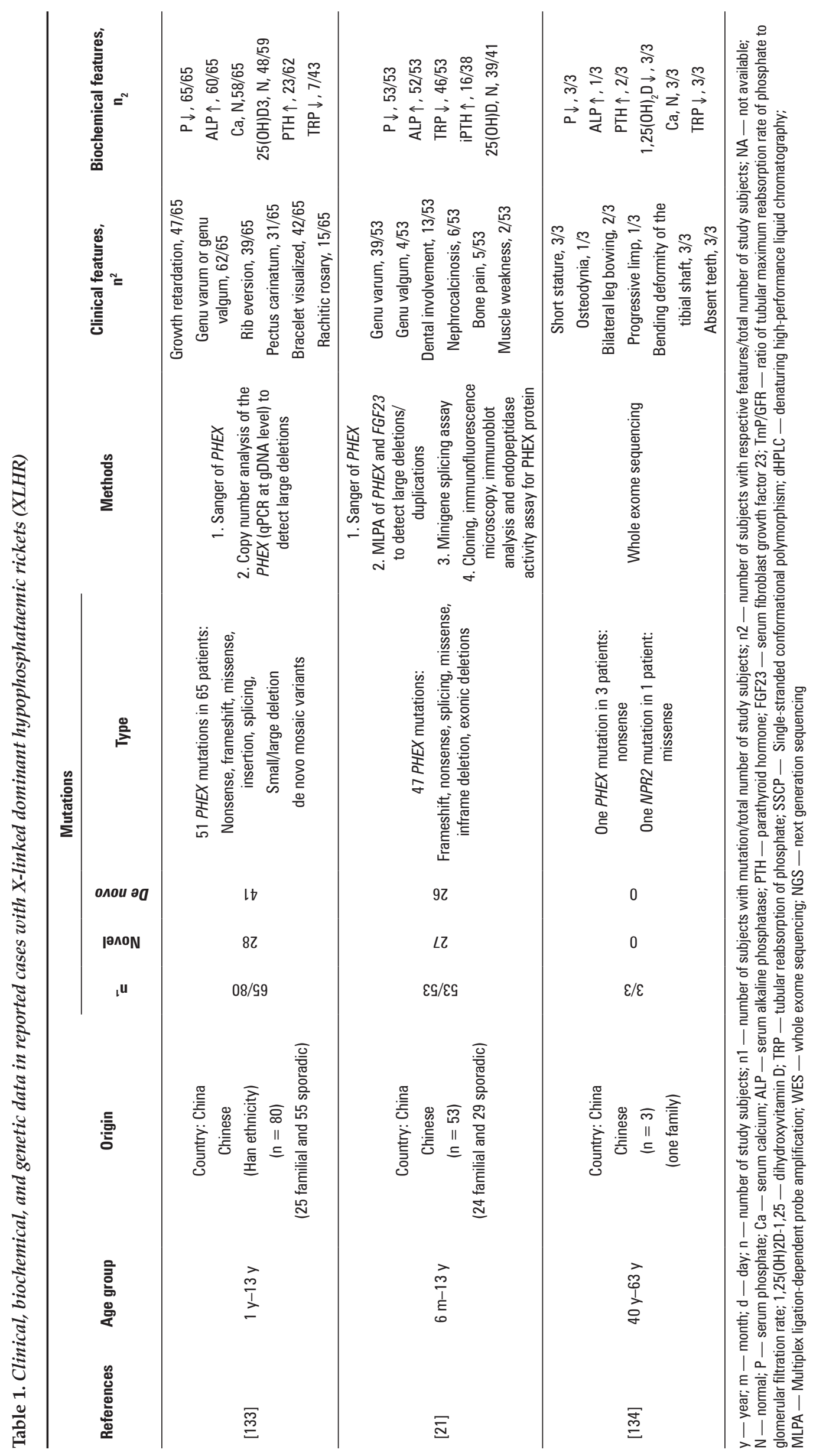


different genetic techniques, but Sanger sequencing has been the most widely used method for mutation screening. In addition to Sanger sequencing, single-stranded conformational polymorphism (SSCP) and denaturing high-performance liquid chromatography (DHPLC) were frequently performed in the 2000s for mutation detection. Multiplex ligation-dependent probe amplification (MLPA) has also been used to screen genes for copy number variation (CNV), usually when the result of Sanger sequencing for the target genes is negative. $\mathrm{CNV}$ analysis is helpful because some HR patients have been reported to have CNV in the PHEX gene [12]. With the evolution of DNA sequencing methods and to overcome the limitations of the Sanger method, next-generation sequencing (NGS) has become the choice sequencing technology; however, Sanger sequencing remains the gold standard and is used to validate the NGS results. In recent times, HR studies have included whole-exome sequencing, as well as targeted panel gene sequencing.

There are 407 different PHEX mutations listed in the Human Gene Mutation Database (HGMD) (public database, accessed January 12, 2021). The majority of PHEX mutations are missense and nonsense, followed by small deletions and splicing mutations (see Tab. 1). The HGMD and other published variants have reported mutations in all exons of PHEX but predominantly in the $3^{\prime}$ end of the gene [13]. The C-terminal segment of the PHEX protein contains the catalytic site and the consensus sequences of the endopeptidases family, to which PHEX belongs [14]. As can be seen in Table 1, novel and de novo PHEX mutations are frequent in HR patients.

A variety of phenotypes are observed among patients with XLHR [3, 15-17], ranging from mild hypophosphataemia to severe bone deformities, which require surgery for correction [17]. Within the same family, members may manifest different features of the disease $[3,13,15,18]$. Observations in XLHR patients showed that there were no significant correlations between genotype and phenotype [17, 19-21], and the phenotype was not gender dependent [22]. Nevertheless, Song et al. [23] reported that patients with mutations in the C-terminal of PHEX showed more severe skeletal disease. Table 1 shows the mutation type and associated phenotype in studies reporting cases with PHEX mutations.

\section{Physical manifestations of XLHR}

Clinical features appear mostly in childhood, with varying severity $[1,16]$. In infancy, the first common feature, which may occur at six months of age, is frontal bossing $[3,8]$. Other clinical features in infancy include rachitic rosary and craniotabes [24]. Primary craniosynostosis, previously not known to be a feature of HR, was recently reported in two unrelated $X$ LHR infants confirmed to have mutations in the PHEX gene [15].

At the end of the first year of life, lower limb deformities appear due to the weight load on the undermineralised bone $[7,8,25]$. As the child starts ambulating, tibial torsion and progressive bowing of the legs become evident $[3,16,24]$. Other physical features are short stature due to decreased height growth $[1,24]$, features of rickets, namely Harrison's sulci, rachitic rosary, swelling of wrists and ankles, and dental abnormalities [1, $6,16,26,27]$. In children, the deformity of lower limbs includes genu varum, genu valgum, and coxa vara. Dental problems consist of noncarious teeth abscess, enamel defects, enlarged pulp chambers, taurodontism [3], and delayed tooth eruption [1]. Dental abscesses result from impaired mineralization of dentin and early decay of lacteal and permanent teeth $[1,18]$.

In adults, a common finding is osteomalacia, which can lead to bone pain and physical dysfunction $[1,3$, $18,28,29]$. Enthesopathy caused by calcification of tendons, ligaments, and joint capsules also occurs [15, $18,24,30,31]$. Furthermore, adults can manifest dental abnormalities such as periodontitis [25, 32, 33], dentin dysplasia [15, 23], and dentinal clefts [23]. Hearing loss has also been described in patients with XLHR, particularly in adulthood. Earlier reports of hearing impairment in XLHR in the 1980s were not genetically confirmed cases. The type of hearing loss reported in adults with XLHR is sensorineural hearing loss [34]. More recently, hearing impairment was described in a Chinese family in which an adult and a child with a novel PHEX mutation had the defect, but two other patients with the same mutation did not show any hearing problems [35].

Due to the variety of clinical signs and the rarity of XLHR, it is often diagnosed late and is therefore difficult to treat. XLHR conventional treatment includes oral phosphate and calcitriol supplementation in children, which cause improvement of rickets, reduced formation of dental abscesses, and prevention of growth failure. However, this treatment is unsuccessful for a significant number of patients [36, 37] and in some cases is associated with problems such as nephrocalcinosis and hyperparathyroidism [38]. For prepubertal children whose height does not improve with conventional treatment, recombinant human growth hormone (rhGH) treatment has been beneficial and has led to an increase in height [39].

Recent HR treatments have been developed based on the pathogenesis of HR. In 2018, burosumab was approved by the US Food and Drug Administration and European Medicines Agency for the treatment of 
XLHR. Burosumab is a human monoclonal antibody that targets FGF23 and corrects the metabolism of vitamin D and levels of serum phosphate [40]. Children with XLHR who received burosumab as a treatment experienced a significant improvement in rickets, growth, and biochemical symptoms compared with patients receiving conventional therapies [38]. In addition to burosumab, other drugs such as the FGF23 receptor antagonist NVP-BGJ398 are being developed and are potential new therapies for XLHR [41].

\section{Biochemical Findings of XLHR}

Typical biochemical findings include hypophosphataemia, reduced tubular resorption of phosphate, and low-normal circulating 1,25-dihydroxyvitamin D $\left(1,25(\mathrm{OH})_{2} \mathrm{D}\right)$ levels. Children present with elevated serum ALP levels. Other laboratory findings show normal serum calcium and circulating 25-hydroxyvita$\min \mathrm{D}$, and elevated levels of circulating FGF23 [1, 42]. Nevertheless, phosphate intake can normalize FGF23 levels in XLHR patients [43]. In untreated patients with low phosphate levels, a FGF23 cut-off level of above $30 \mathrm{pg} / \mathrm{mL}$ is considered for XLHR diagnosis [44]. PTH levels in XLHR are normal or slightly increased $[3,6$, $15,27,42,45]$. For example, approximately half of the newborns with XLHR show slightly elevated levels of PTH [8].

\section{Autosomal dominant hypophosphataemic rickets}

Autosomal dominant hypophosphataemic rickets (ADHR; MIM\# 193100) is due to activating mutations in the FGF23 (MIM\#605380) gene [46]. Identification of the genetic cause of ADHR was the result of positional cloning research that determined a genetic locus on chromosome 12p13.3 [47], and eventually missense mutations, including R176Q, R179Q, and R179W were identified in the FGF23 gene [46]. These FGF23 mutations substitute the arginine residues in the site of protease cleavage. Consequently, intact serum FGF23 levels increase due to FGF23 resistance to cleavage [1, $4,8,18,48-50]$.

Sixteen FGF23 mutations have been reported in HGMD (public database, accessed January 12, 2021); however, only four missense mutations are associated with ADHR (R176Q, R179Q, R176W, and R179W) that localize within the cleavage site of FGF23. According to Table 2, the studies have reported these mutations to be heterozygous and mostly familial, and the incidence of de novo mutations in FGF23 is much lower compared to PHEX.

Recent studies of a HR family with autosomal dominant inheritance identified mutations in the serum/glucocorticoid regulated kinase 3 (SGK3; MIM\#607591) gene, a novel regulator of renal phosphate transport
[51]. In Table 2, the genetic mutations and clinical presentations in reported cases of ADHR, as well as other rare types of $\mathrm{HR}$, are presented.

\section{Physical manifestations of ADHR}

ADHR is characterized by variable age of onset and incomplete penetrance $[1,18,52-55]$. Investigations in three kindreds with ADHR showed that the severity of disease probably depends on FGF23 levels [56]. Different age of onset of clinical manifestations in ADHR patients were first described by Econs and McEnery [55]. Early-onset ADHR presents during childhood, resembling XLHR [3, 57-59], while late-onset ADHR presents during adolescence or adulthood, with different clinical manifestations. Although phosphate levels and growth are normal in childhood, patients manifest after puberty with weakness, bone pain, osteomalacia, osteoporosis, fractures, and rarely lithiasis, but no lower extremity deformities $[3,18,53,55$, 59]. Dental problems such as tooth abscesses $[60,61]$ and dental hypoplasia [59] have also been reported in ADHR patients. A recent study by Liu et al. on patients with ADHR has indicated a genotype-phenotype correlation. This study showed that patients with R179 mutations (R179Q or R179W) had early-onset ADHR and mostly with a history of rickets, while patients with R176 mutations (R176Q or R176W) had late-onset ADHR [60].

\section{Biochemical findings of $A D H R$}

Laboratory findings in ADHR and XLHR patients are similar due to high serum concentrations of FGF23 [3]. In ADHR, the gain-of-function mutations in FGF23 increase intact FGF23 levels, which inhibit renal reabsorption of phosphate, thus causing hypophosphataemia $[62,63]$. Decreased 1,25-dihydroxyvitamin D production in the renal proximal tubules is another consequence of high FGF23 levels, similarly to all types of HR associated with high FGF23 levels [59].

In ADHR, the severity of the disease appears to depend on the concentration of FGF23 [56]. For instance, in some cases of early-onset ADHR, the serum phosphate concentrations and phosphate excretion were observed to return to normal levels in adulthood [54-56, 59, 64], which was associated with normal concentrations of FGF23 in adulthood [56]. Patients with late-onset ADHR are mostly women who manifest severe phosphate wasting and osteomalacia after pregnancy $[53,54]$. It is noteworthy that the late onset in women may indicate the importance of iron status affecting FGF23 levels and phosphate regulation. Women are more prone to develop iron deficiency due to menstruation resulting in monthly blood loss. Some studies have suggested that iron plays a role in regulating FGF23 expression 


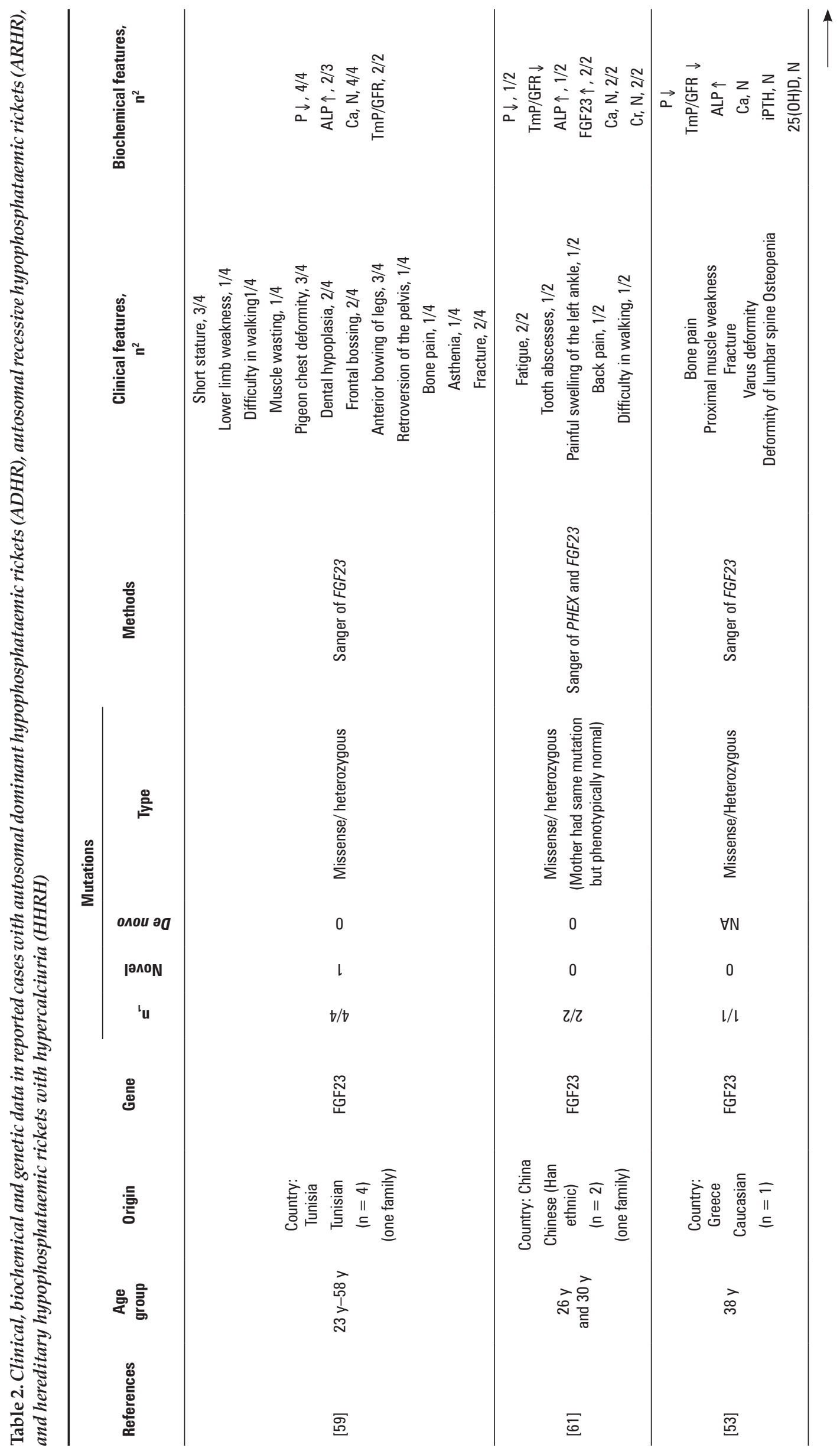




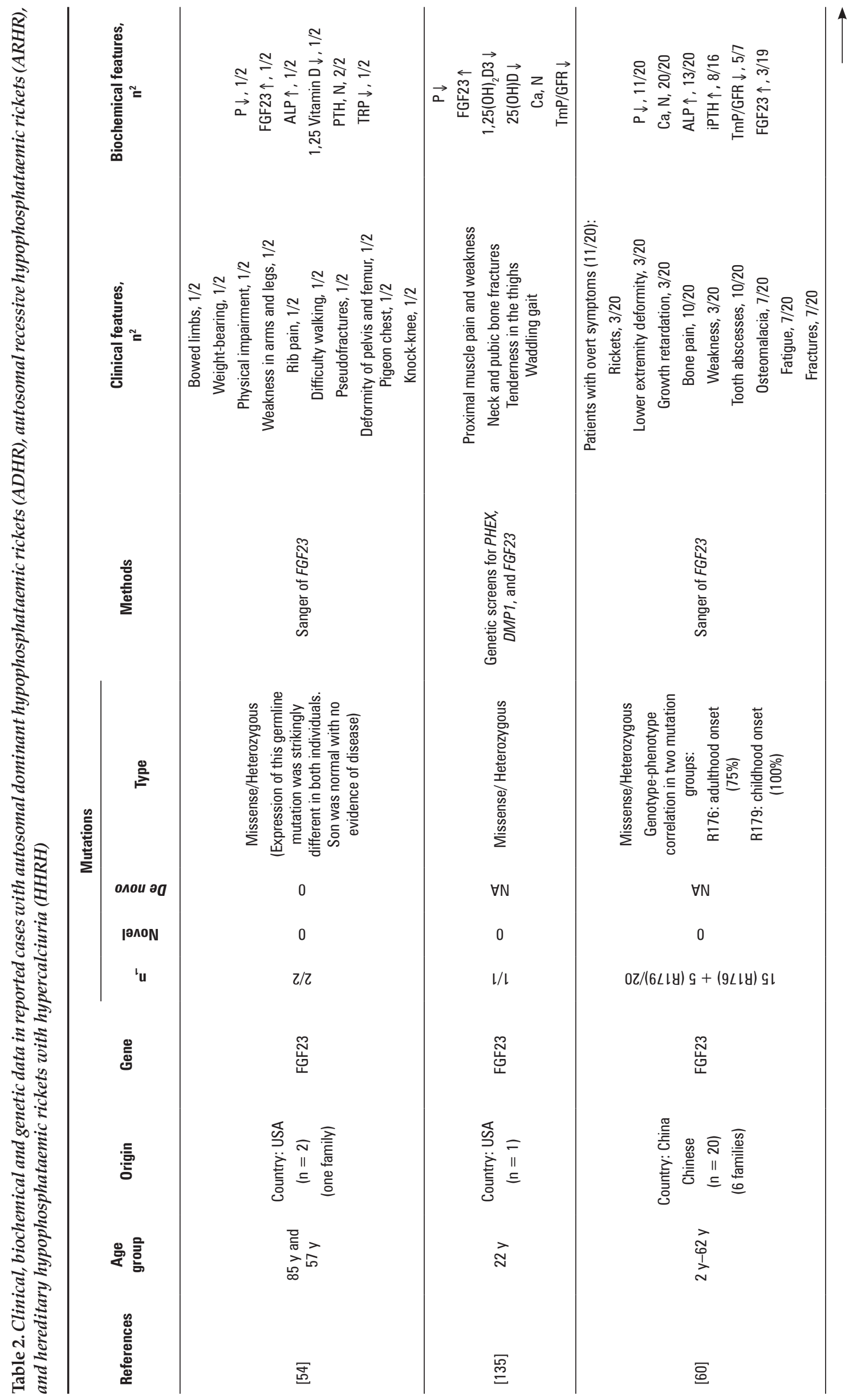




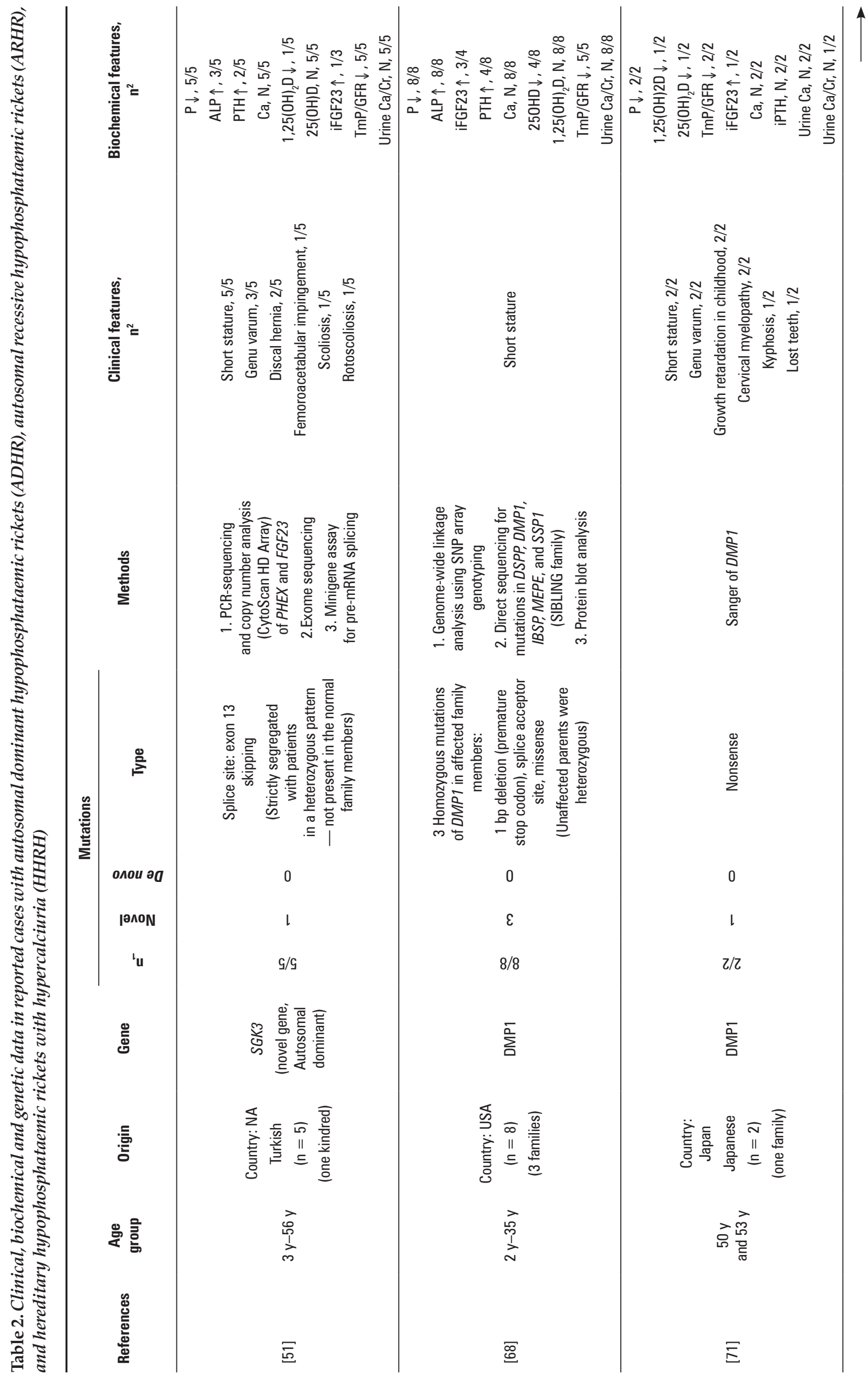




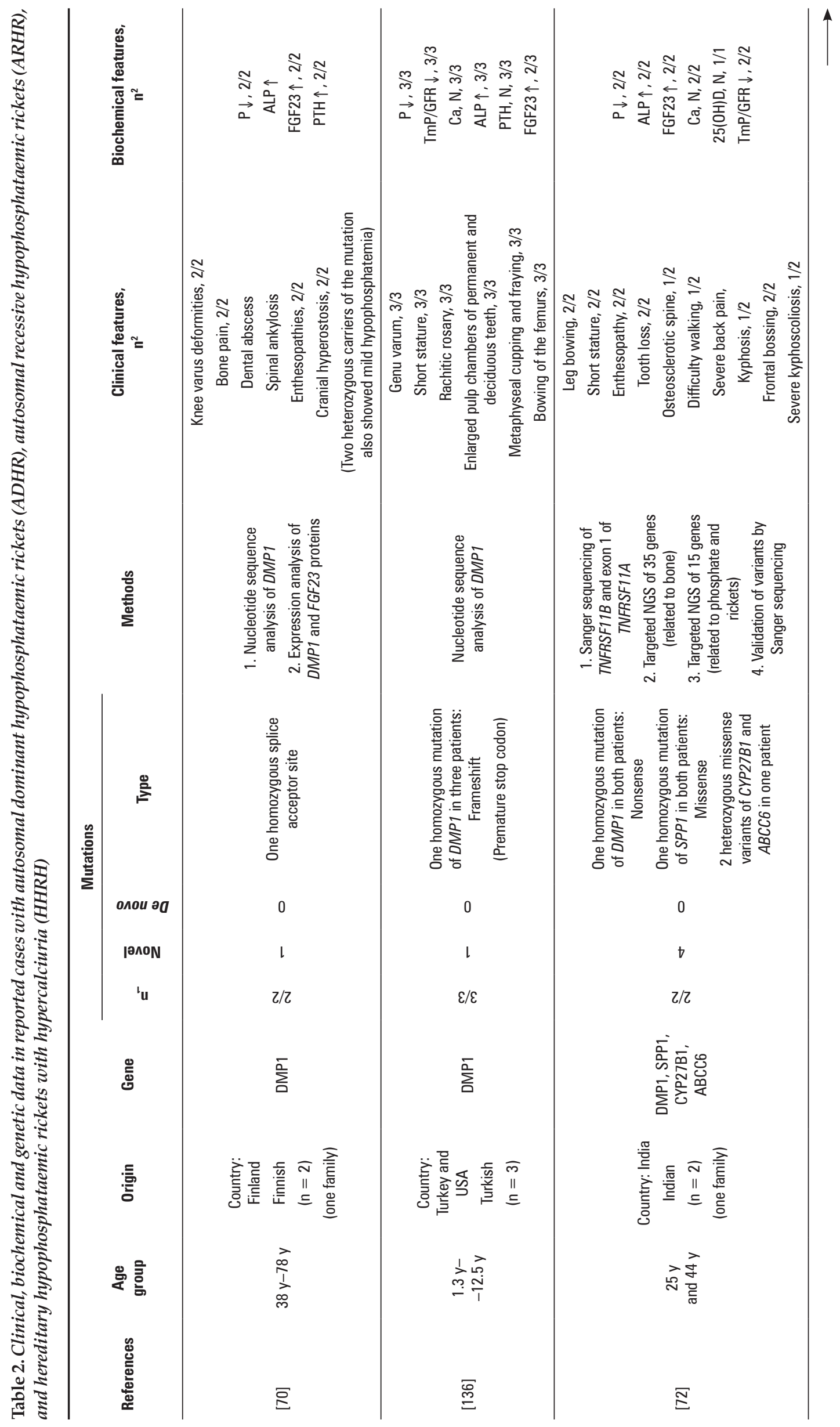




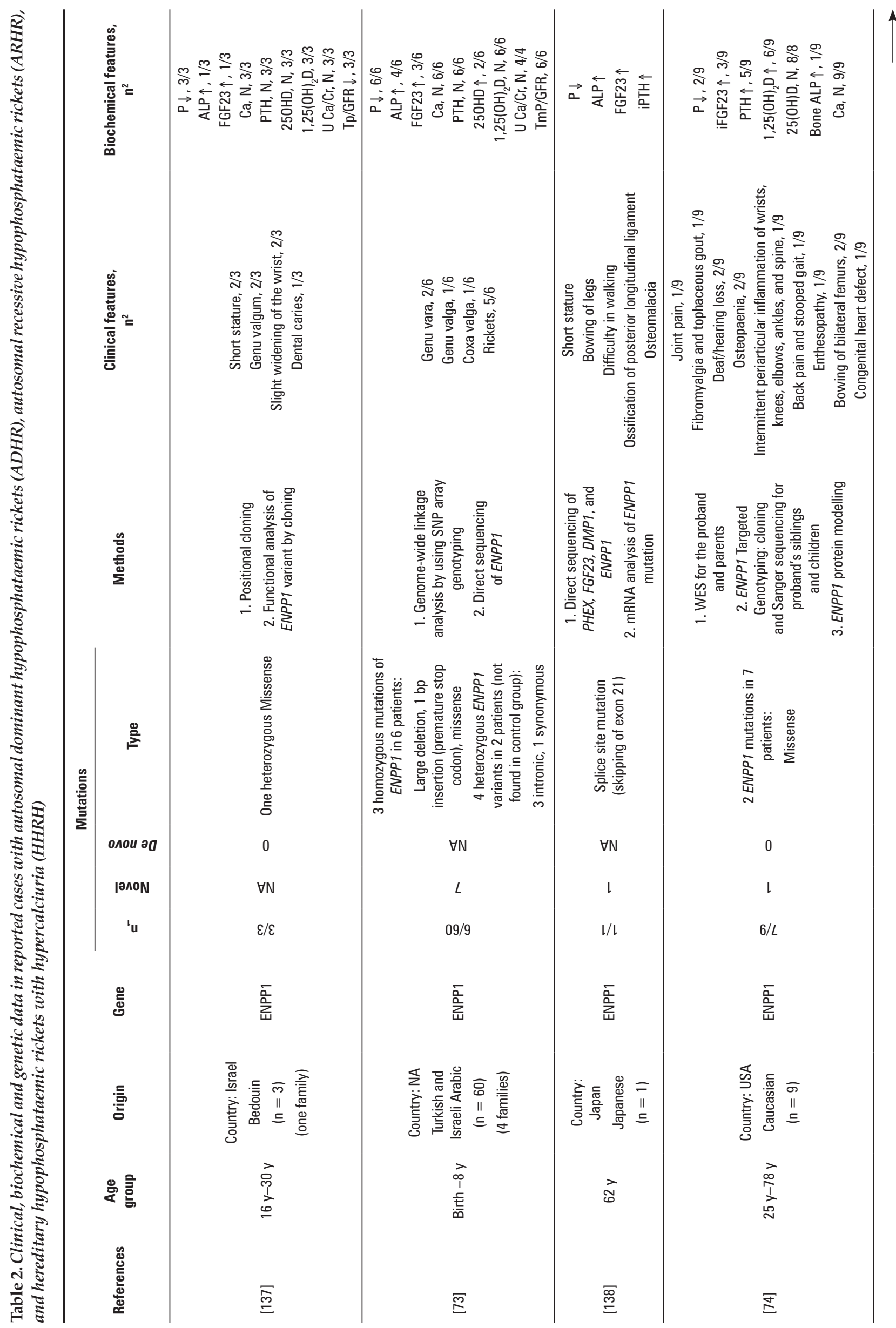




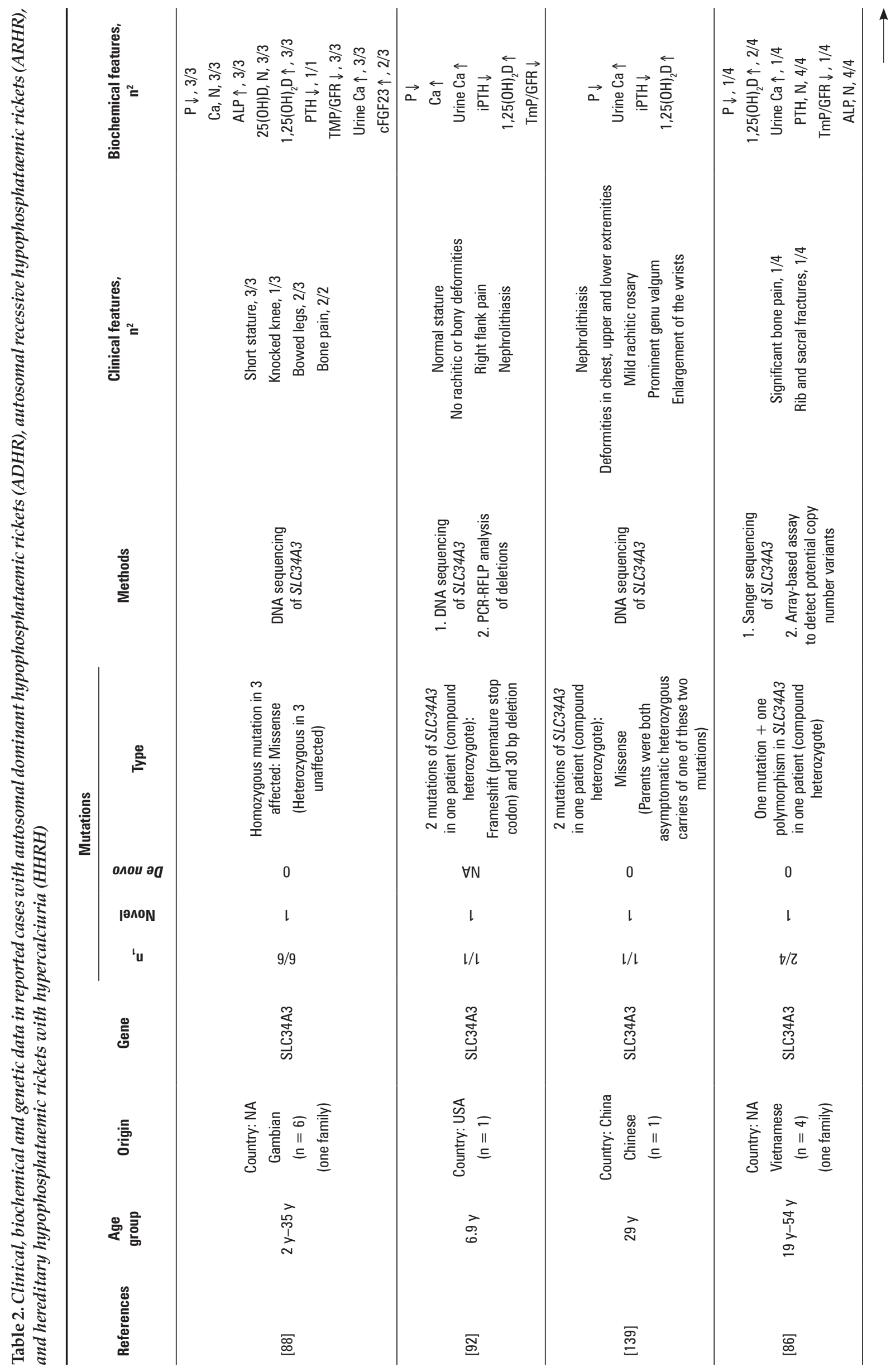




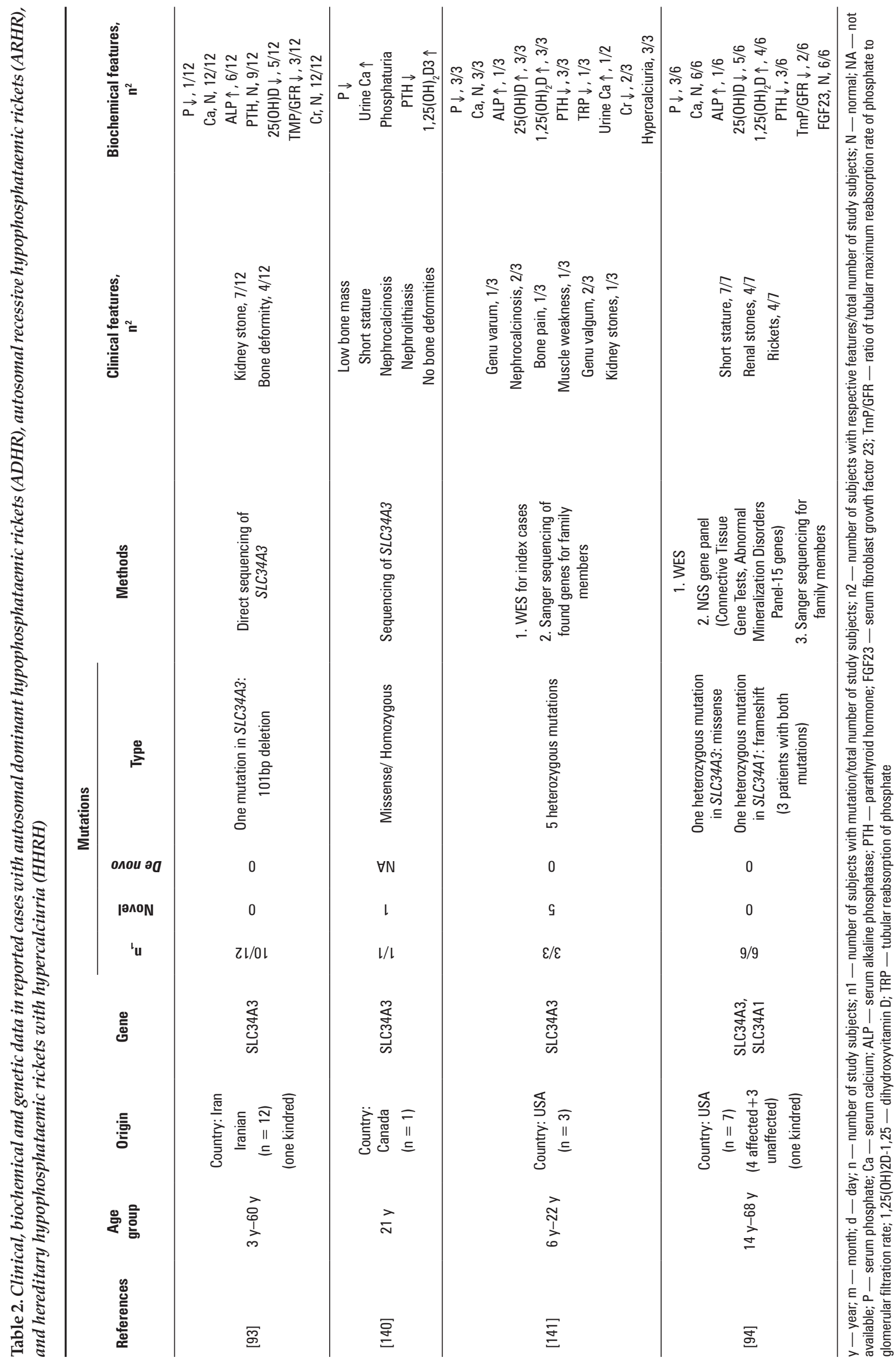


$[65,66]$. In ADHR patients, low serum levels of iron correlate with elevated FGF23 levels, leading to more severe clinical features [67].

\section{Autosomal recessive hypophosphataemic rickets}

Autosomal recessive hypophosphataemic rickets (ARHR) occurs because of inactivating mutations in three genes, namely: DMP1, ENPP1, and FAM20C, resulting in ARHR types 1, 2, and 3, respectively. The physical, biochemical, and radiological features of ARHR in children are similar to those in XLHR and ADHR [3,8]. However, the severity of skeletal disorders in ARHR patients may be more significant than in other types of HR.

ARHR1 (MIM\#241520) is the result of inactivating mutations in the dentin matrix acidic phosphoprotein 1 (DMP1; MIM\#600980) gene [49,68]. DMP1 belongs to small integrin-binding ligand N-linked glycoprotein (SIBLING) and plays an important role in the mineralization of bone and dentin [69]. Nine mutations in DMP1 have been listed in HGMD (public database, accessed January 12, 2021), which are mostly small deletions. There have been no de novo mutations reported thus far. In patients with DMP1 homozygous mutations, dental problems include dental abscesses and tooth loss. The patients also present with skeletal malformations such as rickets, short stature, pathologic fractures, enthesopathies, kyphosis, and spinal ankylosis [70-72]. Osteosclerosis and bone overgrowth may also be observed in some ARHR1 patients [1, 72]. In contrast, heterozygous carriers of a novel splice site mutation in DMP1 (IVS5-1G $>A$ ) have been reported to have focal osteomalacia, but show no features of rickets [70]. Biochemical investigations in healthy heterozygous carriers of this mutation revealed mild hypophosphataemia, elevated bone expression of FGF23, and increased phosphate levels in urine [70].

ARHR2 (MIM\#613312) is due to loss-of-function mutations in the ectonucleotide pyrophosphatase/phosphodiesterase 1 (ENPP1; MIM\#173335) gene, which regulates mineralization of the bone through the matrix vesicle and pyrophosphate pathway [73]. Out of 70 ENPP1 mutations reported in HGMD (public database, accessed January 12, 2021), nine mutations are associated with ARHR2, and the majority are missense mutations. In addition to HR, ENPP1 mutations are also associated with generalized arterial calcification of infancy (GACI), ossification of the posterior longitudinal ligament of the spine, hearing loss during childhood, and insulin resistance $[1,8,18,74]$.

ARHR3 has been linked to loss-of-function mutations in the family with sequence similarity 20 , member C (FAM20C; MIM\#611061) gene [75]. Mutations in
FAM20C were initially found to be the cause of the lethal Raine syndrome, which was characterized by generalized osteosclerosis [76]. Twenty-one FAM20C mutations are listed in HGMD (public database, accessed 12 January 2021) and are mostly associated with osteosclerotic bone dysplasia (Raine syndrome). In human case studies of the non-lethal, milder form of Raine syndrome, individuals with loss-of-function mutations in FAM20C showed osteosclerosis, no features of rickets, but hypophosphataemic osteomalacia [75]. In contrast, a study on Fam20c knock-out mice showed the development of HR, but no osteosclerosis was noted [77]. This phenotypic variation among species may be due to differences in gene expression [78]. Biochemical features in patients with FAM20C mutations are typical of HR and include hypophosphataemia, high levels of urinary phosphate, and increased levels of FGF23. Interestingly, patients with a mild phenotype had normalization of serum phosphate levels after puberty [75]. Severe dental demineralization disease was also reported [75]. A recent study in children with non-lethal Raine syndrome reported clinical and biochemical features of HR such as hypophosphataemia, short stature, and rickets due to mutations in FAM20C [79].

\section{Hypophosphataemic rickets \\ with hyperparathyroidism}

Hypophosphataemic rickets with hyperparathyroidism is very rare, with only one case report so far. It is due to a de novo chromosomal abnormality near the Klotho (KL; MIM\#604824) gene such that a structural variation mutation involving a translocation occurs between chromosomes 13 and 9, and the breakpoint on chromosome 13 is located adjacent to the $K L$ gene. The increase in plasma $\alpha$ Klotho, a subfamily of the Klotho protein family, is the result of this translocation, which eventually leads to elevated levels of FGF23, PTH, and hypercalcaemia, as well as a decrease in serum phosphate and vitamin D3 (cholecalciferol) [8, 80-82].

\section{Hypophosphataemic rickets with normal or low FGF23 levels}

\section{Hereditary hypophosphataemic rickets with hypercalciuria}

The first case of hereditary hypophosphataemic rickets with hypercalciuria (HHRH; MIM\#241530) was reported in a Bedouin kindred who showed an autosomal recessive pattern of inheritance [83]. HHRH is due to homozygous or compound heterozygous inactivating mutations of the solute carrier family 34 (sodium/phosphate co-transporter), member 
3 (SLC34A3; MIM\#609826) gene [84, 85]. There are 36 mutations reported in HGMD (public database, accessed 12 January 2021), of which 17 are missense and nonsense mutations. Most of the SLC34A3 mutations are found to be familial (see Tab. 2). The SLC34A3 gene encodes a type 2 co-transporter of sodium/phosphate $(\mathrm{NaPi} 2 \mathrm{c})$, which is expressed predominantly in the kidney and contributes to controlling inorganic phosphate reabsorption in the renal proximal tubule [1]. The mutations in this gene cause reduced renal reabsorption of phosphate and hypophosphataemia (see Fig. 1). The unique features of $\mathrm{HHRH}$ are high levels of serum $1,25(\mathrm{OH})_{2} \mathrm{D}$ and hypercalciuria, distinguishing it from other types of $\mathrm{HR}[3,8,85]$. The levels of serum PTH are normal or slightly low in patients with HHRH (Tab. 2).

Manifestations of early-onset HHRH include hypophosphataemia, rickets, nephrolithiasis [86-88], and early dental caries [89]. Rarely, carriers with heterozygous mutations of SLC34A3 may have delayed-onset phenotypes [86] manifesting as hypercalciuria and nephrocalcinosis with normal phosphate levels [84, 85, $90,91]$. In HHRH, varying clinical features have been reported among patients from the same family [92-94]. A recent study of a kindred with autosomal dominant inheritance pattern revealed digenic heterozygous mutations in the SLC34A3 and SLC34A1 genes (see Tab. 2). This study was the first report of dominant HHRH. The severity of the disease was higher in patients with both mutations than in those who had only one mutation [94].

\section{$X$-linked recessive hypophosphataemic rickets}

The cause of X-linked recessive hypophosphataemic rickets (MIM\#300554) is loss-of-function mutations in the chloride voltage-gated channel 5 (CLCN5; MIM\#300008) gene [95]. The protein encoded by this gene is a member of the chloride channel (CLC) family [96], which is expressed in renal proximal tubule cells [97]. X-linked recessive HR is referred to as a type of Dent disease complex $[98,99]$. There are 254 mutations reported in HGMD (public database, accessed 12 January 2021) for CLCN5; however, only a few of these mutations are associated with $\mathrm{X}$-linked recessive hypophosphataemic rickets.

There are a few reported kindreds with X-linked recessive hypophosphataemic rickets. The clinical features of $X$-linked recessive hypophosphataemic rickets reported in an Italian family included low serum phosphate levels, rickets or osteomalacia, proteinuria and hypercalciuria followed by the development of nephrocalcinosis in adulthood [100]. A genetic study later confirmed the presence of CLCN5 mutation in this family [95]. The second reported kindred did not demonstrate nephrocalcinosis [101]. More recently, a CLCN5 mutation has been reported in a male teenager with short stature, bowed legs, hypophosphataemia, and medullary nephrocalcinosis [12].

\section{Diagnosis of hypophosphataemic rickets}

Several criteria are considered for the accurate diagnosis of rickets. A strategy that can be useful in diagnosing hypophosphataemic rickets by using clinical features and widely available biochemical tests is summarized in the flowchart in Figure 2. The initial diagnosis of rickets is usually based on physical, radiological, and biochemical features. The data collected in Table 1 and Table 2 show that the hallmarks of HR, including lower limb deformity, hypophosphataemia and elevated ALP, are present in most of the patients studied. The family history is helpful when it is positive. Nonetheless, absence of family history does not preclude the diagnosis of HR because many are due to de novo mutations. Consanguinity increases the risk of genetic diseases. Genetic HR is considered when other conditions that may have HR-like features are ruled out. As can be deduced from Table 1 and 2, blood and urine calcium levels will help in differentiating the type of genetic HR. Furthermore, identifying specific clinical features such as osteosclerosis, early-onset hearing loss, arterial calcification, nephrolithiasis, and nephrocalcinosis will also help to point to a specific type of HR to guide genetic analysis.

\section{Conclusions}

Hypophosphataemic rickets (HR) is a genetic disorder caused by mutations in genes involved with phosphate regulation. These genes include PHEX, FGF23, DMP1, ENPP1, FAM20C, KL, SLC34A3, and CLCN5, which, if mutated, lead to XLHR, ADHR, ARHR1, ARHR2, ARHR3, HR with hyperparathyroidism, HHRH, and $X$-linked recessive $H R$, respectively. The absence of renal loss of other metabolites, including calcium and proteins, suggests FGF23-dependent HR, while the presence of increased amounts of these metabolites in the urine suggests FGF23-independent HR in which the origin of the pathology is in the renal tubule ion transport genes for phosphate. FGF23 measurement could also be used to differentiate FGF23-dependent HR from FGF23-independent HR. However, genetic testing is more reliable for accurate diagnosis of $\mathrm{HR}$. HR typically occurs in childhood with hypophosphataemia and leg deformities. Although several genes and various mutations of these genes contribute to the different types of $\mathrm{HR}$, the phenotype is similar but with variable severity. The presence of clinical features other than 


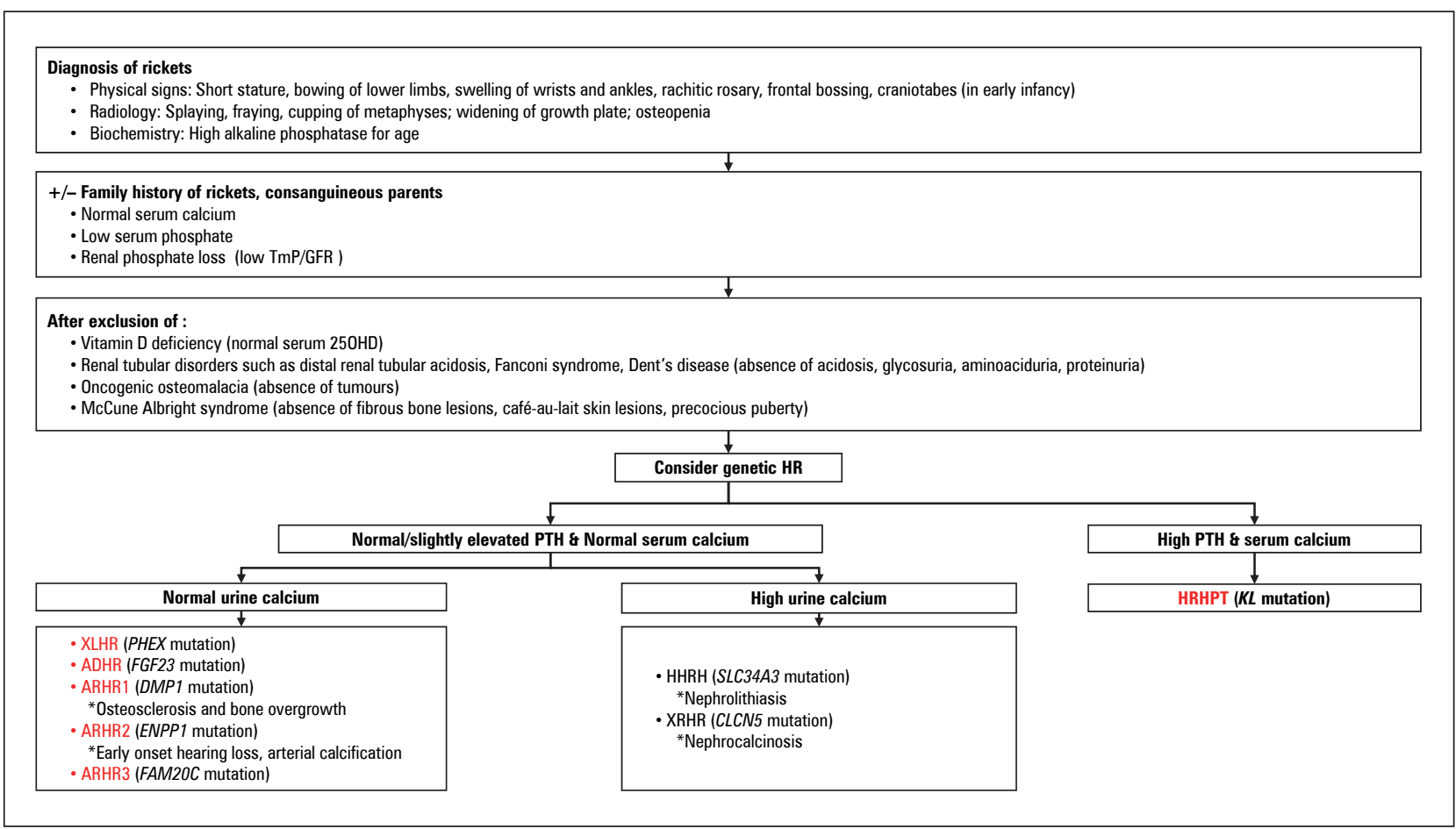

Figure 2. Flow diagram for diagnosing hypophosphataemic rickets. Highlighted in red indicates HR with high serum FGF23 and low or inappropriately normal 1,25-dihyroxyvitamin D levels in the presence of hypophosphataemia. * specific suggestive clinical features to direct genetic testing; TmP/GFR — maximum renal tubular phosphate reabsorption per unit of glomerular filtration rate; $25 \mathrm{OHD}$ - 25-hydroxyvitamin D; HR — hypophosphataemic rickets; HHRH - hereditary hypophosphataemic rickets with hypercalciuria; HRHPT — hypophosphataemic rickets and hyperparathyroidism; XLHR - X-linked hypophosphataemic rickets; ADHR — autosomal dominant hypophosphataemic rickets; XRHR - X-linked recessive hypophosphataemic rickets; ARHR — autosomal recessive hypophosphataemic rickets

rickets can help in determining the rarer types of $\mathrm{HR}$ and direct genetic analysis to look for the specific gene mutation. If the phenotype and genotype of patients with HR are carefully determined, the underlying mechanisms of the disease can be investigated, and this allows the opportunity for rational therapies to be developed.

\section{Funding}

This work was supported by the Ministry of Higher Education, Malaysia [FRGS/1/2016/SKK02/UPM/02/2].

\section{Conflict of interests}

The authors state that they have no conflict of interests.

\section{Acknowledgements}

The authors would like to thank the Ministry of Higher Education Malaysia for funding this study under the grant FRGS/1/2016/SKK02/UPM/02/2.

\section{References}

1. Lambert AS, Linglart A. Hypocalcaemic and hypophosphatemic rickets. Best Pract Res Clin Endocrinol Metab. 2018; 32(4): 455-476, doi: 10.1016/j.beem.2018.05.009, indexed in Pubmed: 30086869.
2. Razali NN,Hwu TT, Thilakavathy K. Phosphate homeostasis and genetic mutations of familial hypophosphatemic rickets. J Pediatr Endocrinol Metab. 2015; 28(9-10): 1009-1017, doi: 10.1515/jpem-2014-0366, indexed in Pubmed: 25894638

3. Jagtap VS, Sarathi V, Lila AR, et al. Hypophosphatemic rickets. Indian J Endocrinol Metab. 2012; 16(2): 177-182, doi: 10.4103/2230-8210.93733, indexed in Pubmed: 22470852

4. Angham A-M AM, Rajaa A. Types of Rickets. Ann Orthop Rheumatol. 2017; 5: 1085.

5. Albright F. Rickets resistant to vitamin D therapy. Arch Ped Adolesc Med 1937; 54(3): 529, doi: 10.1001/archpedi.1937.01980030073005.

6. Lin X, Zhu Y, Luo J, et al. Genetic analysis of three families with Xlinked dominant hypophosphatemic rickets. J Pediatr Endocrinol Metab. 2018; 31(7): 789-797, doi: 10.1515/jpem-2017-0451, indexed in Pubmed: 29858904.

7. Acar S, Demir K, Shi Y. Genetic Causes of Rickets. J Clin Res Pediatr Endocrinol. 2017; 9(Suppl 2): 88-105, doi: 10.4274/jcrpe.2017.S008, indexed in Pubmed: 29280738

8. Bitzan M, Goodyer PR. Hypophosphatemic Rickets. Pediatr Clin North Am. 2019; 66(1): 179-207, doi: 10.1016/j.pcl.2018.09.004, indexed in Pubmed: 30454743

9. Pavone V, Testa G, Gioitta Iachino S, et al. Hypophosphatemic rickets: etiology, clinical features and treatment. Eur J Orthop Surg Traumatol. 2015; 25(2): 221-226, doi: 10.1007/s00590-014-1496-y, indexed in Pubmed: 24957364.

10. Robinson ME, AlQuorain H, Murshed M, et al. Mineralized tissues in hypophosphatemic rickets. Pediatr Nephrol. 2020; 35(10): 1843-1854, doi: 10.1007/s00467-019-04290-y, indexed in Pubmed: 31392510.

11. A gene (PEX) with homologies to endopeptidases is mutated in patients with X-linked hypophosphatemic rickets. The HYP Consortium. Nat Genet. 1995; 11(2): 130-136, doi: 10.1038/ng1095-130, indexed in Pubmed: 7550339.

12. Guven A, Al-Rijjal RA, BinEssa HA, et al. Mutational analysis of PHEX, FGF23 and CLCN5 in patients with hypophosphataemic rickets. Clin Endocrinol (Oxf). 2017; 87(1): 103-112, doi: 10.1111/cen.13347, indexed in Pubmed: 28383812 
13. Ruppe MD, Brosnan PG, Au KS, et al. Mutational analysis of PHEX FGF23 and DMP1 in a cohort of patients with hypophosphatemic rickets. Clin Endocrinol (Oxf). 2011; 74(3): 312-318, doi: 10.1111/j.13652265.2010.03919.x, indexed in Pubmed: 21050253.

14. Filisetti D, Ostermann $G$, von Bredow $M$, et al. Non-random distribution of mutations in the PHEX gene, and under-detected missense mutations at non-conserved residues. Eur J Hum Genet. 1999; 7(5): 615-619, doi: 10.1038/sj.ejhg.5200341, indexed in Pubmed:10439971.

15. Vakharia JD, Matlock K, Taylor HO, et al. Craniosynostosis as the Presenting Feature of X-linked Hypophosphatemic Rickets. Pediatrics. 2018; 141(Suppl 5): S515-S519, doi: 10.1542/peds.2017-2522, indexed in Pubmed: 29610183.

16. Carpenter TO, Imel EA, Holm IA, et al. A clinician's guide to Xlinked hypophosphatemia. J Bone Miner Res. 2011; 26(7): 1381-1388, doi: 10.1002/jbmr.340, indexed in Pubmed: 21538511.

17. Holm IA, Nelson AE, Robinson BG, et al. Mutational analysis and genotype-phenotype correlation of the PHEX gene in X-linked hypophosphatemic rickets. J Clin Endocrinol Metab. 2001; 86(8): 3889-3899, doi: 10.1210/jcem.86.8.7761, indexed in Pubmed: 11502829.

18. Christov M, Jüppner H. Phosphate homeostasis disorders. Best Pract Res Clin Endocrinol Metab. 2018; 32(5): 685-706, doi: 10.1016/j. beem.2018.06.004, indexed in Pubmed: 30449549.

19. Christie PT, Harding B, Nesbit MA, et al. X-linked hypophosphatemia attributable to pseudoexons of the PHEX gene. J Clin Endocrino Metab. 2001; 86(8): 3840-3844, doi: 10.1210/jcem.86.8.7730, indexed in Pubmed: 11502821.

20. Cho HY, Lee BH, Kang JuH, et al. A clinical and molecular genetic study of hypophosphatemic rickets in children. Pediatr Res. 2005; 58(2): 329-333, doi: 10.1203/01.PDR.0000169983.40758.7B, indexed in Pubmed: 16055933.

21. Zheng B, Wang C, Chen $\mathrm{O}$, et al. Functional Characterization of PHEX Gene Variants in Children With X-Linked Hypophosphatemic Rickets Shows No Evidence of Genotype-Phenotype Correlation. J Bone Miner Res. 2020; 35(9): 1718-1725, doi: 10.1002/jbmr.4035, indexed in Pubmed: 32329911.

22. Whyte MP, Schranck FW, Armamento-Villareal R. X-linked hypophosphatemia: a search for gender, race, anticipation, or parent of origin effects on disease expression in children. J Clin Endocrinol Metab. 1996; 81(11): 4075-4080, doi: 10.1210/jcem.81.11.8923863, indexed in Pubmed: 8923863.

23. Song HR, Park JW, Cho DY, et al. PHEX gene mutations and genotype-phenotype analysis of Korean patients with hypophosphatemic rickets. J Korean Med Sci. 2007; 22(6): 981-986, doi: 10.3346/jkms.2007.22.6.981, indexed in Pubmed: 18162710.

24. Ruppe MD, de Beur J. Disorders of phosphate homeostasis. In: Rosen CJ. ed. Primer on the metabolic bone diseases and disorders of mineral metabolism. Wiley Blackwell, New Jersey 2013: 601-612.

25. Boukpessi T, Altabah M, Chaussain C, et al. Endodontic Management of Patients With X Linked Hypophosphatemic Rickets: Case Series Report. Dentistry. 2017; 07(04), doi: 10.4172/2161-1122.1000423.

26. Zivičnjak M, Schnabel D, Billing $\mathrm{H}$, et al. Hypophosphatemic Ricket Study Group of Arbeitsgemeinschaft für Pädiatrische Endokrinologie and Gesellschaft für Pädiatrische Nephrologie. Age-related stature and linear body segments in children with X-linked hypophosphatemic rickets. Pediatr Nephrol. 2011; 26(2): 223-231, doi: 10.1007/s00467-010-1705-9, indexed in Pubmed: 21120538.

27. Murthy AS. X-linked hypophosphatemic rickets and craniosynostosis.JCraniofac Surg. 2009; 20(2): 439-442, doi: 10.1097/SCS.0b013e31819b9868, indexed in Pubmed: 19242361.

28. Che H, Roux C, Etcheto A, et al. Impaired quality of life in adults with X-linked hypophosphatemia and skeletal symptoms. Eur J Endocrinol. 2016; 174(3): 325-333, doi: 10.1530/EJE-15-0661, indexed in Pubmed: 26783348.

29. Reid IR, Hardy DC, Murphy WA, et al. X-linked hypophosphatemia: a clinical, biochemical, and histopathologic assessment of morbidity in adults. Medicine (Baltimore). 1989; 68(6): 336-352, indexed in Pubmed: 2811660.

30. Capelli S, Donghi V, Maruca K, et al. Clinical and molecular heterogeneity in a large series of patients with hypophosphatemic rickets. Bone. 2015; 79: 143-149, doi: 10.1016/j.bone.2015.05.040, indexed in Pubmed: 26051471.

31. Pereira CM, de Andrade CR, Vargas PA, et al. Dental alterations associated with X-linked hypophosphatemic rickets. J Endod. 2004 30(4): 241-245, doi: 10.1097/00004770-200404000-00015, indexed in Pubmed: 15085056.

32. Chaussain-Miller C, Sinding C, Wolikow M, et al. Dental abnormalities in patients with familial hypophosphatemic vitamin D-resistan rickets: prevention by early treatment with 1-hydroxyvitamin D. J Pediatr. 2003; 142(3): 324-331, doi: 10.1067/mpd.2003.119, indexed in Pubmed: 12640383.

33. Biosse Duplan M, Coyac BR, Bardet C, et al. Phosphate and Vitamin D Prevent Periodontitis in X-Linked Hypophosphatemia. J Den
Res. 2017; 96(4): 388-395, doi: 10.1177/0022034516677528, indexed in Pubmed: 27821544

34. Fishman G, Miller-Hansen D, Jacobsen C, et al. Hearing impairment in familial X-linked hypophosphatemic rickets. Eur J Pediatr. 2004; 163(10): 622-623, doi: 10.1007/s00431-004-1504-z, indexed in Pubmed: 15290264.

35. Yuan L, Wu S, Xu H, et al. Identification of a novel PHEX mutation in a Chinese family with X-linked hypophosphatemic rickets using exome sequencing. Biol Chem. 2015; 396(1): 27-33, doi: 10.1515/hsz-2014-0187, indexed in Pubmed: 25060345

36. Haffner D, Emma F, Eastwood DM, et al. Clinical practice recommendations for the diagnosis and management of $X$-linked hypophosphataemia. Nat Rev Nephrol. 2019; 15(7): 435-455, doi: 10.1038/s41581-019-0152-5, indexed in Pubmed: 31068690.

37. Obara-Moszynska M, Rojek A, Kolesinska Z, et al. X-linked hypophosphataemic rickets in children: clinical phenotype, therapeutic strategies, and molecular background. Endokrynol Pol. 2021; 72(2): 108-119 doi: 10.5603/EP.a2020.0087, indexed in Pubmed: 33295632.

38. Imel EA, Glorieux FH, Whyte MP, et al. Burosumab versus conventional therapy in children with X-linked hypophosphataemia: a randomised, active-controlled, open-label, phase 3 trial. Lancet. 2019, 393(10189): 2416-2427, doi: 10.1016/S0140-6736(19)30654-3, indexed in Pubmed: 31104833

39. Rothenbuhler A, Esterle L, Gueorguieva I, et al. Two-year recombinant human growth hormone (rhGH) treatment is more effective in pre-pubertal compared to pubertal short children with X-linked hypophosphatemic rickets (XLHR). Growth Horm IGF Res. 2017; 36: 11-15, doi: 10.1016/j.ghir.2017.08.001, indexed in Pubmed: 28822957.

40. Zhang C, Zhao Z, Sun Y, et al. Clinical and genetic analysis in a large Chinese cohort of patients with X-linked hypophosphatemia. Bone. 2019; 121: 212-220, doi: 10.1016/j.bone.2019.01.021, indexed in Pubmed: 30682568.

41. Wöhrle S, Henninger C, Bonny O, et al. Pharmacological inhibition of fibroblast growth factor (FGF) receptor signaling ameliorates FGF23-mediated hypophosphatemic rickets. J Bone Miner Res. 2013; 28(4): 899-911, doi: 10.1002/jbmr.1810, indexed in Pubmed: 23129509.

42. Fuente R, Gil-Peña H, Claramunt-Taberner D, et al. X-linked hypophosphatemia and growth. Rev Endocr Metab Disord. 2017; 18(1): 107-115, doi: 10.1007/s11154-017-9408-1, indexed in Pubmed: 28130634.

43. Yamazaki Y, Okazaki R, Shibata M, et al. Increased circulatory level of biologically active full-length FGF-23 in patients with hypophosphatemic rickets/osteomalacia. J Clin Endocrinol Metab. 2002; 87(11): 4957-4960, doi: 10.1210/jc.2002-021105, indexed in Pubmed: 12414858.

44. Endo I, Fukumoto S, Ozono K, et al. Clinical usefulness of measurement of fibroblast growth factor 23 (FGF23) in hypophosphatemic patients: proposal of diagnostic criteria using FGF23 measurement. Bone. 2008; 42(6): 1235-1239, doi: 10.1016/j.bone.2008.02.014, indexed in Pubmed: 18396126.

45. Bastepe M, Jüppner $\mathrm{H}$. Inherited hypophosphatemic disorders in children and the evolving mechanisms of phosphate regulation. Rev Endocr Metab Disord. 2008; 9(2): 171-180, doi: 10.1007/s11154-008-9075-3, indexed in Pubmed: 18365315.

46. ADHR Consortium. Autosomal dominant hypophosphataemic rickets is associated with mutations in FGF23. Nat Genet. 2000; 26(3): 345-348, doi: 10.1038/81664, indexed in Pubmed: 11062477.

47. Econs MJ, McEnery PT Lennon F et al Autosomal dominant hypophosphatemic rickets is linked to chromosome 12p13. J Clin Invest. 1997; 100(11): 2653-2657, doi: 10.1172/JCI119809, indexed in Pubmed: 9389727.

48. Takeda E, Yamamoto H, Nashiki K, et al. Inorganic phosphate homeostasis and the role of dietary phosphorus. J Cell Mol Med. 2004; 8(2): 191-200, doi: 10.1111/j.1582-4934.2004.tb00274.x, indexed in Pubmed: 15256067

49. Feng JQ, Ward LM, Liu S, et al. Loss of DMP1 causes rickets and osteomalacia and identifies a role for osteocytes in mineral metabolism. Nat Genet. 2006; 38(11): 1310-1315, doi: 10.1038/ng1905, indexed in Pubmed: 17033621

50. White KE, Carn G, Lorenz-Depiereux B, et al. Autosomal-dominant hypophosphatemic rickets (ADHR) mutations stabilize FGF-23. Kidney Int. 2001; 60(6): 2079-2086, doi: 10.1046/j.1523-1755.2001.00064.x, indexed in Pubmed: 11737582

51. Cebeci AN, Zou M, BinEssa HA, et al. Mutation of SGK3, a Novel Regulator of Renal Phosphate Transport, Causes Autosomal Dominan Hypophosphatemic Rickets. J Clin Endocrinol Metab. 2020; 105(6), doi: 10.1210/clinem/dgz260, indexed in Pubmed: 31821448

52. White KE, Jonsson KB, Carn G, et al. The autosomal dominant hypophosphatemic rickets (ADHR) gene is a secreted polypeptide overexpressed by tumors that cause phosphate wasting. J Clin Endocrinol Metab. 2001; 86(2): 497-500, doi: 10.1210/jcem.86.2.7408, indexed in Pubmed: 11157998.

53. Tournis S, Koromila T, Chatzistamatas N, et al. Hip fracture leading to the diagnosis of autosomal dominant hypophosphatemic rickets. A case report. J Musculoskelet Neuronal Interact. 2013; 13: 391-394, indexed in Pubmed: 23989261. 
54. Seton M, Jüppner H. Autosomal dominant hypophosphatemic rickets in an 85 year old woman: characterization of her disease from infancy through adulthood. Bone. 2013; 52(2): 640-643, doi: 10.1016/j. bone.2012.11.012, indexed in Pubmed: 23174215.

55. Econs MJ, McEnery PT. Autosomal dominant hypophosphatemic rickets/osteomalacia: clinical characterization of a novel renal phosphate-wasting disorder. J Clin Endocrinol Metab. 1997; 82(2): 674-681, doi: 10.1210/jcem.82.2.3765, indexed in Pubmed: 9024275.

56. Imel EA, Hui SL, Econs MJ. FGF23 concentrations vary with disease status in autosomal dominant hypophosphatemic rickets. J Bone Miner Res. 2007; 22(4): 520-526, doi: 10.1359/jbmr.070107, indexed in Pubmed: 17227222.

57. Imel EA, Econs MJ. Approach to the hypophosphatemic patient. J Clin Endocrinol Metab. 2012; 97(3): 696-706, doi: 10.1210/jc.2011-1319, indexed in Pubmed: 22392950.

58. Pettifor JM, Thandrayen K. Hypophosphatemic rickets: unraveling the role of FGF23. Calcif Tissue Int. 2012; 91(5): 297-306, doi: 10.1007/s00223-012-9651-0, indexed in Pubmed: 23001439.

59. Gribaa M, Younes M, Bouyacoub Y, et al. An autosomal dominant hypophosphatemic rickets phenotype in a Tunisian family caused by a new FGF23 missense mutation. J Bone Miner Metab. 2010; 28(1): 111-115, doi: 10.1007/s00774-009-0111-5, indexed in Pubmed: 19655082.

60. Liu C, Zhao Z, Wang Ou, et al. Earlier Onset in Autosomal Dominant Hypophosphatemic Rickets of R179 than R176 Mutations in Fibroblast Growth Factor 23: Report of 20 Chinese Cases and Review of the Literature. Calcif Tissue Int. 2019; 105(5): 476-486, doi: 10.1007/s00223-019-00597-y, indexed in Pubmed: 31486862

61. Sun Y, Wang Ou, Xia W, et al. FGF23 analysis of a Chinese family with autosomal dominant hypophosphatemic rickets. J Bone Miner Metab. 2012; 30(1): 78-84, doi: 10.1007/s00774-011-0285-5, indexed in Pubmed: 21710177.

62. Benet-Pagès A, Orlik P, Strom TM, et al. An FGF23 missense mutation causes familial tumoral calcinosis with hyperphosphatemia. Hum Mol Genet. 2005; 14(3): 385-390, doi: 10.1093/hmg/ddi034, indexed in Pubmed: 15590700.

63. Larsson T, Davis SI, Garringer HJ, et al. Fibroblast growth factor-23 mutants causing familial tumoral calcinosis are differentially processed. Endocrinology. 2005; 146(9): 3883-3891, doi: 10.1210/en.2005-0431, indexed in Pubmed: 15961556.

64. Kruse K, Woelfel D, Strom TM, et al. Loss of renal phosphate wasting in a child with autosomal dominant hypophosphatemic rickets caused by a FGF23 mutation. Horm Res. 2001; 55(6): 305-308, doi: 10.1159/000050018, indexed in Pubmed: 11805436.

65. Kinoshita Y, Fukumoto S. X-Linked Hypophosphatemia and FGF23-Related Hypophosphatemic Diseases: Prospect for New Treatment. Endocr Rev. 2018; 39(3): 274-291, doi: 10.1210/er.2017-00220, indexed in Pubmed: 29381780.

66. Shimizu Y, Tada Y, Yamauchi M, et al. Hypophosphatemia induced by intravenous administration of saccharated ferric oxide: another form of FGF23-related hypophosphatemia. Bone. 2009; 45(4): 814-816, doi: 10.1016/j.bone.2009.06.017, indexed in Pubmed: 19555782.

67. Imel EA, Peacock M, Gray AK, et al. Iron modifies plasma FGF23 differently in autosomal dominant hypophosphatemic rickets and healthy humans. J Clin Endocrinol Metab. 2011; 96(11): 3541-3549, doi: 10.1210/jc.2011-1239, indexed in Pubmed: 21880793.

68. Lorenz-Depiereux B, Bastepe M, Benet-Pagès A, et al. DMP1 mutations in autosomal recessive hypophosphatemia implicate a bone matrix protein in the regulation of phosphate homeostasis. Nat Genet. 2006; 38(11): 1248-1250, doi: 10.1038/ng1868, indexed in Pubmed: 17033625.

69. Farrow EG, Davis SI, Ward LM, et al. Molecular analysis of DMP1 mutants causing autosomal recessive hypophosphatemic rickets. Bone. 2009; 44(2): 287-294, doi: 10.1016/j.bone.2008.10.040, indexed in Pubmed: 19007919.

70. Mäkitie O, Pereira RC, Kaitila I, et al. Long-term clinical outcome and carrier phenotype in autosomal recessive hypophosphatemia caused by a novel DMP1 mutation. J Bone Miner Res. 2010; 25(10): 2165-2174, doi: 10.1002/jbmr.105, indexed in Pubmed: 20499351.

71. Koshida R, Yamaguchi H, Yamasaki K, et al. A novel nonsense mutation in the DMP1 gene in a Japanese family with autosomal recessive hypophosphatemic rickets. J Bone Miner Metab. 2010; 28(5): 585-590, doi: 10.1007/s00774-010-0169-0, indexed in Pubmed: 20213538.

72. Whyte MP, Amalnath SD, McAlister WH, et al. Hypophosphatemic osteosclerosis, hyperostosis, and enthesopathy associated with novel homozygous mutations of DMP1 encoding dentin matrix protein 1 and SPP1 encoding osteopontin: The first digenic SIBLING protein osteopathy? Bone. 2020; 132: 115190, doi: 10.1016/j.bone.2019.115190, indexed in Pubmed: 31843680

73. Lorenz-Depiereux B, Schnabel D, Tiosano D, et al. Loss-of-function ENPP1 mutations cause both generalized arterial calcification of infancy and autosomal-recessive hypophosphatemic rickets. Am J Hum Genet. 2010; 86(2): 267-272, doi: 10.1016/j.ajhg.2010.01.006, indexed in Pubmed: 20137773.
74. Kotwal A, Ferrer A, Kumar R, et al. Clinical and Biochemical Phenotypes in a Family With ENPP1 Mutations. J Bone Miner Res. 2020; 35(4): 662-670, doi: 10.1002/jbmr.3938, indexed in Pubmed: 31826312

75. Rafaelsen $\mathrm{SH}$, Raeder H, Fagerheim AK, et al. Exome sequencing reveals FAM20c mutations associated with fibroblast growth factor 23-related hypophosphatemia, dental anomalies, and ectopic calcification. J Bone Miner Res. 2013; 28(6): 1378-1385, doi: 10.1002/jbmr.1850, indexed in Pubmed: 23325605.

76. Simpson MA, Hsu R, Keir LS, et al. Mutations in FAM20C are associated with lethal osteosclerotic bone dysplasia (Raine syndrome), highlighting a crucial molecule in bone development. Am J Hum Genet. 2007; 81(5): 906-912, doi: 10.1086/522240, indexed in Pubmed: 17924334.

77. Wang $X$, Wang S, Li C, et al. Inactivation of a novel FGF23 regulator FAM20C, leads to hypophosphatemic rickets in mice. PLoS Genet. 2012; 8(5): e1002708, doi: 10.1371/journal.pgen.1002708, indexed in Pubmed: 22615579 .

78. Harries LW, Brown JE, Gloyn AL Species-specific differences in the expression of the HNF1A, HNF1B and HNF4A genes. PLoS One. 2009; 4(11): e7855, doi: 10.1371/journal.pone.0007855, indexed in Pubmed: 19924231

79. Mameli C, Zichichi G, Mahmood N, et al. Natural history of non-lethal Raine syndrome during childhood. Orphanet J Rare Dis. 2020; 15(1): 93, doi: 10.1186/s13023-020-01373-0, indexed in Pubmed: 32299476.

80. Erben RG. $\alpha$-Klotho's effects on mineral homeostasis are fibroblast growth factor-23 dependent. Curr Opin Nephrol Hypertens. 2018; 27(4) 229-235, doi: 10.1097/MNH.0000000000000415, indexed in Pubmed: 29851418.

81. Rowe PS. A unified model for bone-renal mineral and energy metabolism. Curr Opin Pharmacol. 2015; 22: 64-71, doi: 10.1016/j. coph.2015.03.006, indexed in Pubmed: 25880364.

82. Smith RC, O'Bryan LM, Farrow EG, et al. Circulating $\alpha$ Klotho influences phosphate handling by controlling FGF23 production. J Clin Invest. 2012; 122(12): 4710-4715, doi: 10.1172/JCI64986, indexed in Pubmed 23187128.

83. Tieder M, Modai D, Shaked U, et al. Hereditary hypophosphatemic rickets with hypercalciuria. N Engl J Med. 1985; 312(10): 611-617, doi: 10.1056/NEJM198503073121003, indexed in Pubmed: 2983203.

84. Bergwitz C, Roslin NM, Tieder M, et al. SLC34A3 mutations in patients with hereditary hypophosphatemic rickets with hypercalciuria predict a key role for the sodium-phosphate cotransporter NaPi-IIc in maintaining phosphate homeostasis. Am J Hum Genet. 2006; 78(2): 179-192, doi: 10.1086/499409, indexed in Pubmed: 16358214.

85. Lorenz-Depiereux B, Benet-Pages A, Eckstein G, et al. Hereditary hypophosphatemic rickets with hypercalciuria is caused by mutations in the sodium-phosphate cotransporter gene SLC34A3. Am J Hum Genet. 2006; 78(2): 193-201, doi: 10.1086/499410, indexed in Pubmed: 16358215.

86. Dhir G, Li D, Hakonarson H, et al. Late-onset hereditary hypophosphatemic rickets with hypercalciuria $(\mathrm{HHRH})$ due to mutation of SLC34A3/NPT2c. Bone. 2017; 97: 15-19, doi: 10.1016/j.bone.2016.12.001, indexed in Pubmed: 27939817

87. Page K, Bergwitz C, Jaureguiberry G, et al. A patient with hypophosphatemia, a femoral fracture, and recurrent kidney stones: report of a novel mutation in SLC34A3. Endocr Pract. 2008; 14(7): 869-874, doi: 10.4158/EP.14.7.869, indexed in Pubmed: 18996815.

88. Braithwaite V, Pettifor JM, Prentice A. Novel SLC34A3 mutation causing hereditary hypophosphataemic rickets with hypercalciuria in a Gambian family. Bone. 2013; 53(1): 216-220, doi: 10.1016/j.bone.2012.12.003 indexed in Pubmed: 23246670.

89. Hasani-Ranjbar S, Amoli MM, Ebrahim-Habibi A, et al. SLC34A3 intronic deletion in a new kindred with hereditary hypophosphatemic rickets with hypercalciuria. J Clin Res Pediatr Endocrinol. 2012; 4(2): 89-93, doi: 10.4274/jcrpe.601, indexed in Pubmed: 22672866.

90. Wagner CA, Rubio-Aliaga I, Hernando N. Renal phosphate handling and inherited disorders of phosphate reabsorption: an update. Pediatr Nephrol. 2019; 34(4): 549-559, doi: 10.1007/s00467-017-3873-3, indexed in Pubmed: 29275531

91. Dasgupta D, Wee MJ, Reyes M, et al. Mutations in SLC34A3/NPT2C are associated with kidney stones and nephrocalcinosis. J Am Soc Nephrol. 2014; 25(10): 2366-2375, doi: 10.1681/ASN.2013101085, indexed in Pubmed: 24700880

92. Ichikawa S, Tuchman S, Padgett LR, et al. Intronic deletions in the SLC34A3 gene: a cautionary tale for mutation analysis of hereditary hypophosphatemic rickets with hypercalciuria. Bone. 2014; 59: 53-56, doi: 10.1016/j.bone.2013.10.018, indexed in Pubmed: 24176905.

93. Hasani-Ranjbar S, Ejtahed HS, Amoli MM, et al. Intronic Deletion in an Iranian Kindred with Hereditary Hypophosphatemic Rickets with Hypercalciuria. J Clin Res Pediatr Endocrinol. 2018; 10(4): 343-349, doi: 10.4274/jcrpe.0057, indexed in Pubmed: 29809158.

94. Gordon RJ, Li D, Doyle D, et al. Digenic Heterozygous Mutations in SLC34A3 and SLC34A1 Cause Dominant Hypophosphatemic Rickets with Hypercalciuria. J Clin Endocrinol Metab. 2020; 105(7), doi: 10.1210/clinem/dgaa217, indexed in Pubmed: 32311027. 
95. Lloyd SE, Pearce SH, Fisher SE, et al. A common molecular basis for three inherited kidney stone diseases. Nature. 1996; 379(6564): 445-449, doi: 10.1038/379445a0, indexed in Pubmed: 8559248.

96. Fisher SE, van Bakel I, Lloyd SE, et al. Cloning and characterization of CLCN5, the human kidney chloride channel gene implicated in Den disease (an X-linked hereditary nephrolithiasis). Genomics. 1995; 29(3): 598-606, doi: 10.1006/geno.1995.9960, indexed in Pubmed: 8575751.

97. Günther W, Lüchow A, Cluzeaud F, et al. ClC-5, the chloride channel mutated in Dent's disease, colocalizes with the proton pump in endocytotically active kidney cells. Proc Natl Acad Sci U S A. 1998; 95(14): 8075-8080, doi: 10.1073/pnas.95.14.8075, indexed in Pubmed: 9653142

98. Scheinman SJ. X-linked hypercalciuric nephrolithiasis: clinical syndromes and chloride channel mutations. Kidney Int. 1998; 53(1): 3-17, doi: 10.1046/j.1523-1755.1998.00718.x, indexed in Pubmed: 9452994.

99. Gambaro G, Vezzoli G, Casari G, et al. Genetics of hypercalciuria and calcium nephrolithiasis: from the rare monogenic to the common polygenic forms. Am J Kidney Dis. 2004; 44(6): 963-986, doi: 10.1053/j ajkd.2004.06.030, indexed in Pubmed: 15558518.

100. Bolino A, Devoto M, Enia G, et al. Genetic mapping in the Xp11.2 region of a new form of X-linked hypophosphatemic rickets. Eur J Hum Genet. 1993; 1(4): 269-279, doi: 10.1159/000472424, indexed in Pubmed: 7915957.

101. Oudet C, Martin-Coignard D, Pannetier S, et al. A second family with XLRH displays the mutation S244L in the CLCN5 gene. Hum Genet. 1997; 99(6): 781-784, doi: 10.1007/s004390050448, indexed in Pubmed: 9187673

102. Dixon PH, Christie PT, Wooding C, et al. Mutational analysis of PHEX gene in X-linked hypophosphatemia. J Clin Endocrinol Metab. 1998; 83(10): 3615-3623, doi: 10.1210/jcem.83.10.5180, indexed in Pubmed: 9768674

103. Tyynismaa H, Kaitila I, Näntö-Salonen K, et al. Identification of fifteen novel PHEX gene mutations in Finnish patients with hypophosphatemic rickets. Hum Mutat. 2000; 15(4): 383-384, doi: 10.1002/(SICI)1 098-1004(200004)15:4<383::AID-HUMU18>3.0.CO;2-\#, indexed in Pubmed: 10737991.

104. Goji K, Ozaki K, Sadewa AH, et al. Somatic and germline mosaicism for a mutation of the PHEX gene can lead to genetic transmission of X-linked hypophosphatemic rickets that mimics an autosomal dominant trait. J Clin Endocrinol Metab. 2006; 91(2): 365-370, doi: 10.1210/jc.2005-1776, indexed in Pubmed: 16303832.

105. Xia W, Meng X, Jiang Y, et al. Three novel mutations of the PHEX gene in three Chinese families with X-linked dominant hypophosphatemic rickets. Calcif Tissue Int. 2007; 81(6): 415-420, doi: 10.1007/s00223-007-9067-4, indexed in Pubmed: 18046499.

106. Ichikawa S, Traxler EA, Estwick SA, et al. Mutational survey of the PHEX gene in patients with $X$-linked hypophosphatemic rickets. Bone. 2008; 43(4): 663-666, doi: 10.1016/j.bone.2008.06.002, indexed in Pubmed: 18625346.

107. Saito T, Nishii Y, Yasuda T, et al. Familial hypophosphatemic ricket caused by a large deletion in PHEX gene. Eur J Endocrinol. 2009; 161(4): 647-651, doi: 10.1530/EJE-09-0261, indexed in Pubmed: 19581284.

108. Gaucher C, Walrant-Debray O, Nguyen TM, et al. PHEX analysis in 118 pedigrees reveals new genetic clues in hypophosphatemic rickets. Hum Genet. 2009; 125(4): 401-411, doi: 10.1007/s00439-009-0631-z, indexed in Pubmed: 19219621.

109. Beck-Nielsen SS, Brusgaard K, Rasmussen LM, et al. Phenotype presentation of hypophosphatemic rickets in adults. Calcif Tissue Int. 2010; 87(2): 108-119, doi: 10.1007/s00223-010-9373-0, indexed in Pubmed: 20524110.

110. Morey M, Castro-Feijóo L, Barreiro J, et al. Genetic diagnosis of X-linked dominant Hypophosphatemic Rickets in a cohort study: tubular reabsorption of phosphate and 1,25(OH)2D serum levels are associated with PHEX mutation type. BMC Med Genet. 2011; 12: 116, doi: 10.1186/1471-2350-12-116, indexed in Pubmed: 21902834.

111. Beck-Nielsen SS, Brixen K, Gram J, et al. Mutational analysis of PHEX, FGF23, DMP1, SLC34A3 and CLCN5 in patients with hypophosphatemic rickets. J Hum Genet. 2012; 57(7): 453-458, doi: 10.1038/jhg.2012.56, indexed in Pubmed: 22695891.

112. Kinoshita Y, Saito T, Shimizu Y, et al. Mutational analysis of patients with FGF23-related hypophosphatemic rickets. Eur J Endocrinol. 2012 167(2): 165-172, doi: 10.1530/EJE-12-0071, indexed in Pubmed: 22577109.

113. Durmaz E, Zou M, Al-Rijjal RA, et al. Novel and de novo PHEX mutations in patients with hypophosphatemic rickets. Bone. 2013; 52(1): 286-291, doi: 10.1016/j.bone.2012.10.012, indexed in Pubmed: 23079138

114. Dayal D, Sharda S, Attri SV, et al. Hypophosphatemic rickets caused by a novel PHEX gene mutation in an Indian girl. J Pediatr Endocrino Metab. 2014; 27(7-8): 787-789, doi: 10.1515/jpem-2013-0270, indexed in Pubmed: 24756041

115. Pekkarinen T, Lorenz-Depiereux B, Lohman M, et al. Unusually severe hypophosphatemic rickets caused by a novel and complex re-arrangement of the PHEX gene. Am J Med Genet A. 2014; 164A(11): 2931-2937, doi: 10.1002/ajmg.a.36721, indexed in Pubmed: 25124877.
116. Radlović V, Smoljanić Z, Radlović N, et al. X-linked hypophosphatemic rickets: case report. Srp Arh Celok Lek. 2014; 142(1-2): 75-78, doi: 10.2298/sarh1402075r, indexed in Pubmed: 24684036.

117. Mumm S, Huskey M, Cajic A, et al. PHEX 3'-UTR c.*231A>G near the polyadenylation signal is a relatively common, mild, American mutation that masquerades as sporadic or X-linked recessive hypophosphatemic rickets. J Bone Miner Res. 2015; 30(1): 137-143, doi: 10.1002/jbmr.2307, indexed in Pubmed: 25042154.

118. Ma SL, Vega-Warner V, Gillies C, et al. Whole Exome Sequencing Reveals Novel PHEX Splice Site Mutations in Patients with Hypophosphatemic Rickets. PLoS One. 2015; 10(6): e0130729, doi: 10.1371/journal. pone.0130729, indexed in Pubmed: 26107949

119. Rafaelsen S, Johansson S, Ræder H, et al. Hereditary hypophosphatemia in Norway: a retrospective population-based study of genotypes, phenotypes, and treatment complications. Eur J Endocrinol. 2016, 174(2): 125-136, doi: 10.1530/EJE-15-0515, indexed in Pubmed: 26543054.

120. Weng C, Chen J, Sun Li, et al. A de novo mosaic mutation of PHEX in a boy with hypophosphatemic rickets. J Hum Genet. 2016; 61(3): 223-227, doi: 10.1038/jhg.2015.133, indexed in Pubmed: 26559751.

121. Gu J, Wang C, Zhang H, et al. Targeted resequencing of phosphorus metabolism-related genes in 86 patients with hypophosphatemic rickets/osteomalacia. Int J Mol Med. 2018; 42(3): 1603-1614, doi: 10.3892/ijmm.2018.3730, indexed in Pubmed: 29901142.

122. Rothenbuhler A, Fadel N, Debza Y, et al. High Incidence of Cranial Synostosis and Chiari I Malformation in Children With X-Linked Hypophosphatemic Rickets (XLHR). J Bone Miner Res. 2019; 34(3): 490-496, doi: 10.1002/jbmr.3614, indexed in Pubmed: 30352126.

123. Guerboub AA, Moussaoui S, Issouani J, et al. X-linked vitamin D-resistant rickets: 12 years of follow-up. Pan Afr Med J. 2018 30: 9, doi: 10.11604/pamj.2018.30.9.14762, indexed in Pubmed 30123412.

124. Acar S, BinEssa HA, Demir K, et al. Clinical and genetic characteristics of 15 families with hereditary hypophosphatemia: Novel Mutations in PHEX and SLC34A3. PLoS One. 2018; 13(3): e0193388, doi: 10.1371/journal.pone.0193388, indexed in Pubmed: 29505567.

125. Goljanek-Whysall K, Tridimas A, McCormick R, et al. Identification of a novel loss-of-function PHEX mutation, Ala720Ser, in a sporadic case of adult-onset hypophosphatemic osteomalacia. Bone. 2018; 106: 30-34, doi: 10.1016/j.bone.2017.10.002, indexed in Pubmed: 28982589.

126. Yang M, Kim J, Yang A, et al. A novel de novo mosaic mutation in PHEX in a Korean patient with hypophosphatemic rickets. Ann Pediatr Endocrinol Metab. 2018; 23(4): 229-234, doi: 10.6065/apem.2018.23.4.229, indexed in Pubmed: 30599486.

127. Jin P, Wang LH, Mo ZH. Identification a novel insertion PHEX mutation in a sporadic patient with hypophosphatemic rickets. J Endocrino Invest. 2019; 42(3): 357-359, doi: 10.1007/s40618-018-0976-z, indexed in Pubmed: 30406928

128. Sako S, Niida Yo, Shima KR, et al. A novel mutation associated with vitamin D-resistant rickets. Hum Genome Var. 2019; 6: 9 , doi: 10.1038/s41439-019-0040-3, indexed in Pubmed: 30792871.

129. Lee KS, Lee BoL. The first Korean case report with scaphocephaly as the initial sign of X-linked hypophosphatemic rickets. Childs Nerv Syst. 2019; 35(6): 1045-1049, doi: 10.1007/s00381-018-04042-7, indexed in Pubmed: 30613854

130. Li W, Tan L, Li X, et al. Identification of a p.Trp403* nonsense variant in PHEX causing X-linked hypophosphatemia by inhibiting p38 MAPK signaling. Hum Mutat. 2019; 40(7): 879-885, doi: 10.1002/humu.23743, indexed in Pubmed: 30920082.

131. Şıklar Z, Turan S, Bereket A, et al. Nationwide Turkish Cohort Study of Hypophosphatemic Rickets. J Clin Res Pediatr Endocrinol. 2020; 12(2): 150-159, doi: 10.4274/jcrpe.galenos.2019.2019.0098, indexed in Pubmed: 31514490

132. Razali NN, Tzer HT, King HL, et al. Predicting the Impact of PHEX, FGF23 and DMP1 Gene Variants Found in Malaysian Malay Patients with Hypophosphataemic Rickets Through In Silico Analysis of Protein Function and mRNA Secondary Structure. J Biochem Microbio Biotechnol. 2019; 7: 14-23.

133. Lin $\mathrm{Y}, \mathrm{Xu} \mathrm{J}, \mathrm{Li} \mathrm{X}$, et al. Novel variants and uncommon cases among southern Chinese children with X-linked hypophosphatemia. J Endocrinol Invest. 2020; 43(11): 1577-1590, doi: 10.1007/s40618-020-01240-6, indexed in Pubmed: 32253725.

134. Zhao Y, Yang F, Wang L, et al. Familial hypophosphatemic rickets caused by a PHEX gene mutation accompanied by a NPR2 missense mutation. JPediatr Endocrinol Metab. 2020; 33(2): 305-311, doi: 10.1515/jpem-2019-0380, indexed in Pubmed: 31927522.

135. Mualla H, Bae SuAh, Yaqub A. Autosomal Dominant Hypophosphatemic Rickets Presenting in a Phenotypically Normal Adult Female. Case Rep Endocrinol. 2019; 2019: 8917519, doi: 10.1155/2019/8917519, indexed in Pubmed: 30949368 
136. Turan S, Aydin C, Bereket A, et al. Identification of a novel dentin matrix protein-1 (DMP-1) mutation and dental anomalies in a kindred with autosomal recessive hypophosphatemia. Bone. 2010; 46(2): 402-409, doi: 10.1016/j.bone.2009.09.016, indexed in Pubmed: 19796717.

137. Levy-Litan V, Hershkovitz E, Avizov L, et al. Autosomal-recessive hypophosphatemic rickets is associated with an inactivation mutation in the ENPP1 gene. Am J Hum Genet. 2010; 86(2): 273-278, doi: 10.1016/j. ajhg.2010.01.010, indexed in Pubmed: 20137772.

138. Saito T, Shimizu Y, Hori M, et al. A patient with hypophosphatemic rickets and ossification of posterior longitudinal ligament caused by a novel homozygous mutation in ENPP1 gene. Bone. 2011; 49(4): 913-916, doi: 10.1016/j.bone.2011.06.029, indexed in Pubmed: 21745613.
139. Chi Y, Zhao Z, He X, et al. A compound heterozygous mutation in SLC34A3 causes hereditary hypophosphatemic rickets with hypercalciuria in a Chinese patient. Bone. 2014; 59: 114-121, doi: 10.1016/j. bone.2013.11.008, indexed in Pubmed: 24246249.

140. Tang A, Hinz L, Khan A, et al. Phosphate matters when investigating hypercalcemia: a mutation in SLC34A3 causing HHRH. Endocrinol Diabetes Metab Case Rep. 2019; 2019(1): 1-6, doi: 10.1530/EDM-19-0058, indexed in Pubmed: 31352694

141. Chen A, Ro H, Mundra VR, et al. Description of 5 Novel NPT2c Mutations Causing Hereditary Hypophosphatemic Rickets With Hypercalciuria. Kidney Int Rep. 2019; 4(8): 1179-1186, doi: 10.1016/j.ekir.2019.05.004, indexed in Pubmed: 31440709. 